Portland State University

PDXScholar

Fall 1-20-2017

\title{
Teacher and Student Perceptions of World Englishes (WE) Pronunciations in two US Settings
}

\author{
Marie Arrieta \\ Portland State University
}

Follow this and additional works at: https://pdxscholar.library.pdx.edu/open_access_etds

Part of the Applied Linguistics Commons, and the First and Second Language Acquisition Commons Let us know how access to this document benefits you.

\section{Recommended Citation}

Arrieta, Marie, "Teacher and Student Perceptions of World Englishes (WE) Pronunciations in two US Settings" (2017). Dissertations and Theses. Paper 3411.

https://doi.org/10.15760/etd.5309

This Thesis is brought to you for free and open access. It has been accepted for inclusion in Dissertations and Theses by an authorized administrator of PDXScholar. Please contact us if we can make this document more accessible: pdxscholar@pdx.edu. 
Teacher and Student Perceptions of World Englishes (WE)

Pronunciations in two US Settings

by

Marie Arrieta

A thesis submitted in partial fulfillment of the requirements for the degree of

\author{
Master of Arts \\ in \\ Teaching English to Speakers of Other Languages
}

Thesis Committee:

Kimberley Brown, Chair

Lynn Santelmann

Jeff Conn

Portland State University

2016 


\begin{abstract}
The present study investigated the perceptions and attitudes of two groups each of ESL teachers and students in the United States regarding World Englishes (WE) pronunciations before and after watching a video on WE accents. Data gathered via online surveys were analyzed using a combination of quantitative and qualitative methods. The results show that the perceptions of the teachers in the study ranged from somewhat negative to mildly positive, both pre- and post-video, which is consistent with Brown's (1993) findings that teachers' perceptions changed little if at all after being briefly exposed to WE stimuli. The education of the teachers in this study did not seem to influence their responses, either. Both groups of teachers responded almost identically even though the Midwest (MW) teachers' education ranged from no TESOL training to MA TESOL and all the teachers in the Northwest (NW) had MA TESOL degrees. These teachers' exposure to WE topics also varied greatly from teacher to teacher. Although the results of the study could not establish a correlation between lack of WE exposure and lack of WE classroom implementation, the teacher responses were, again, consistent with the literature in that the advantages of WE implementation are often appreciated only after extensive training on the matter. Student results were slightly more encouraging than their teachers', as students were generally more enthusiastic about WE before and after stimuli. A majority of students surveyed expressed they would like their teachers to incorporate more WE materials into their lessons and, after watching the video, all but one student indicated they would take an Accents of the World class as they considered it “important to learn about the ways people in other parts of the world speak English".
\end{abstract}




\section{Dedication}

I dedicate this study to Dr. Kimberley Brown, my thesis advisor, inexhaustible fountain of knowledge, and main supporter throughout this process. Your compassion and encouragement through difficult times inspired me to push ahead even when I doubted myself. I am forever grateful for your guidance and support.

I also dedicate this study to non-native ELTs everywhere. Because I know how challenging it can be, at times, to be one. 


\section{Acknowledgments}

I would like to thank my husband and the best partner in life I could have hoped for, Adam, for supporting me every step of the way. I would have never been able to devote this much time and effort to this study without your loving support and encouragement. I would also like to thank my committee advisors, Dr. Lynn Santelmann and Dr. Jeff Conn, for their thoughtful insights and feedback. Lastly, I would like to thank my friend, Eric, for listening to endless chatter about WE and linguistics, just because he is that great a friend. 


\section{Table of Contents}

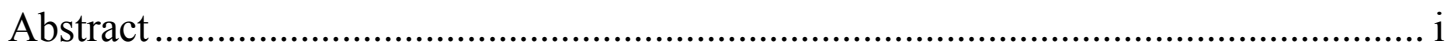

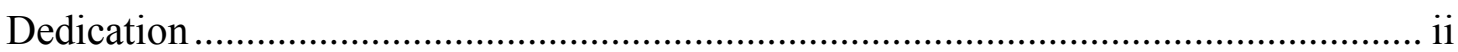

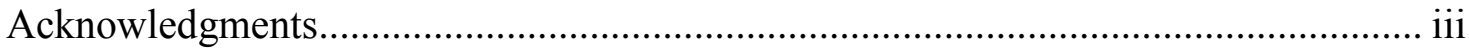

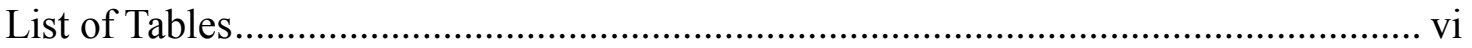

List of Figures ........................................................................................... vii

Chapter 1: Introduction ................................................................................ 1

Discrimination based on Accent ........................................................................ 3

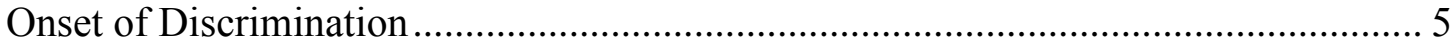

Personal Background and Motivation for this Study .......................................... 6

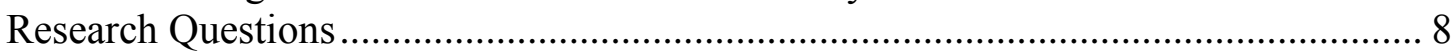

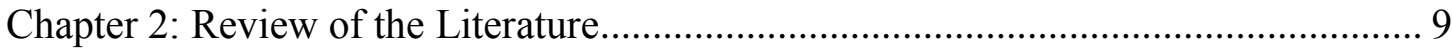

Theoretical-Conceptual Basis for this Study ........................................................ 10

Supporting Framework for the Successful Incorporation of WE in the Classroom ...... 10

Student vs. Teacher-Centered Classrooms ........................................................ 10

Kumaravadivelu's Perceptual Mismatches ....................................................... 13

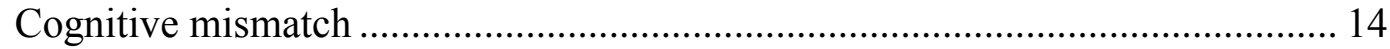

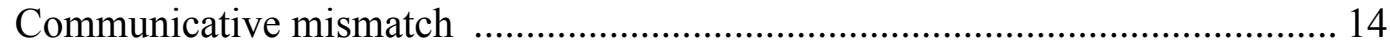

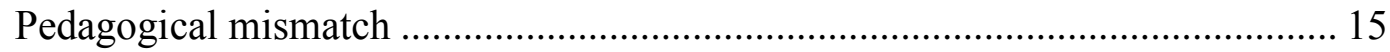

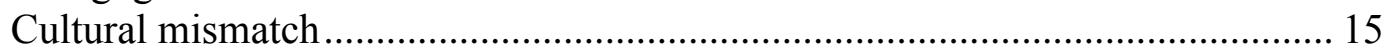

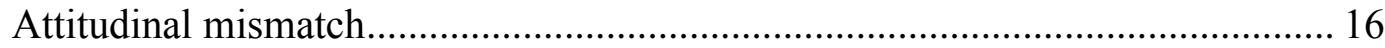

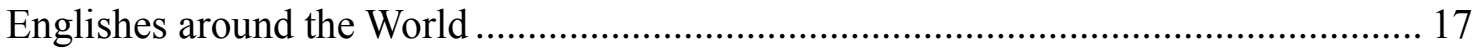

Kachru's World Englishes Paradigm ..................................................................... 18

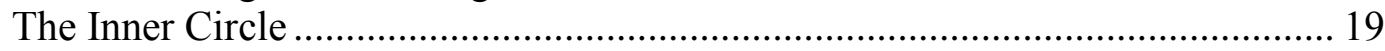

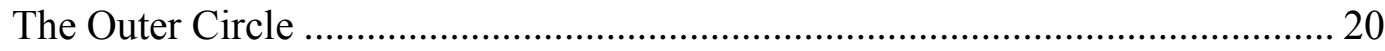

The Expanding Circle ........................................................................... 21

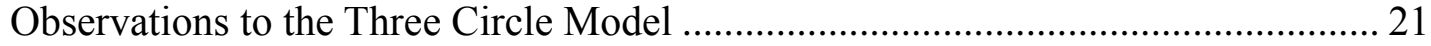

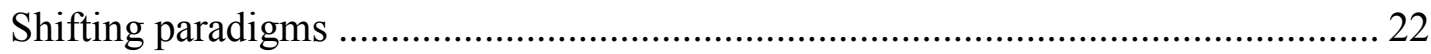

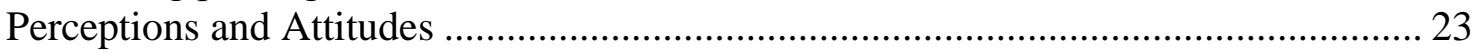

ELT attitudes and perceptions ...................................................................... 24

Factors that influence ELTs' perceptions and attitudes about their practice ............ 24

Personal factors that influence teacher attitudes and perceptions....................... 24

Cognition and teachers' maxims.................................................................. 25

Professional training and teaching experience............................................ 26

Contributing factors to teacher attitudes regarding WE and pronunciation instruction ....28

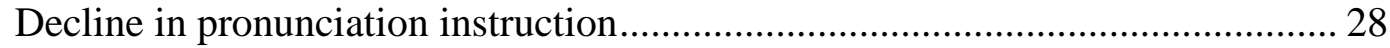

Lack of inter/multicultural training and awareness ........................................ 29

Teacher preference for the nativeness model.............................................. 30

The nativeness and the intelligibility principles .......................................... 31

Intelligibility, Comprehensibility and Accent................................................ 33 
Students' perceptions and attitudes toward EL pronunciation ................................... 35

Factors that influence English L2 phonology attainment in students ...................... 35

Student perceptions of NNES accent with regard to pronunciation instruction........ 36

Literature regarding student self-perceptions of accent ..................................... 38

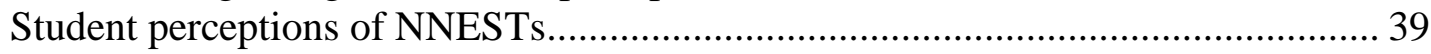

EL Pronunciation Teaching Through the Years .................................................. 40

Pronunciation Materials and WE Focus .............................................................. 42

English as a Lingua Franca (ELF) and the Lingua Franca Core (LFC)....................... 44

Conclusion to this Section ................................................................................. 46

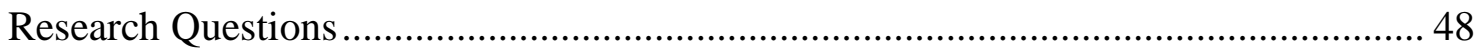

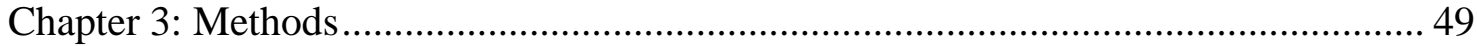

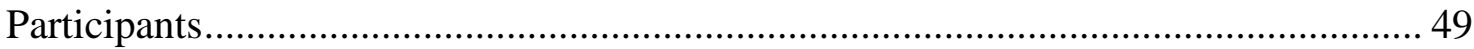

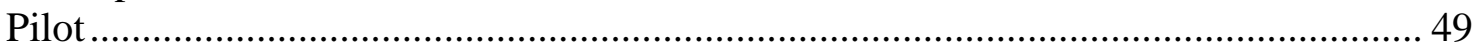

Instruments and Materials ............................................................................. 50

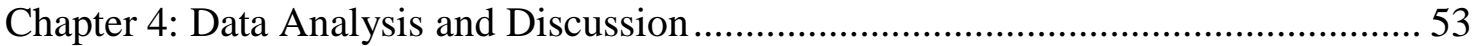

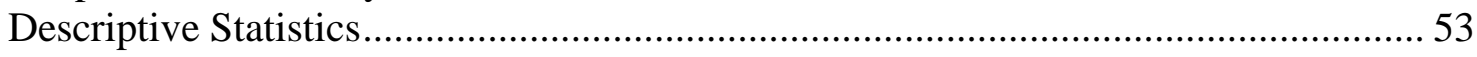

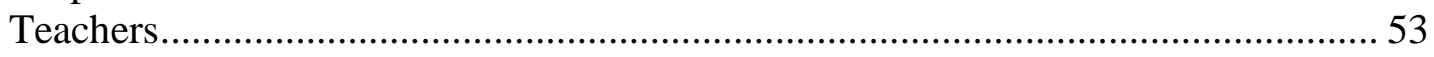

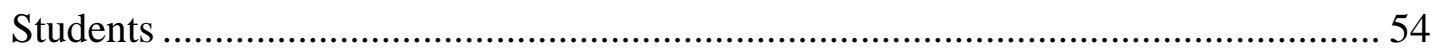

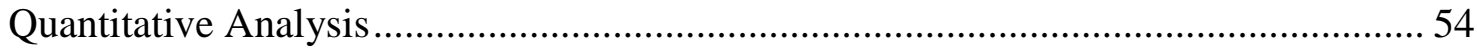

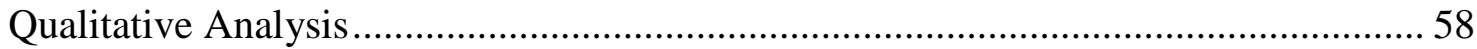

Perceptions about accented English .............................................................. 58

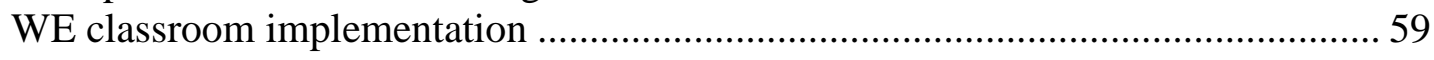

Self-perception of accent as a predictor of classroom WE implementation ............. 61

Teacher perception of the importance of WE in their own practice .......................62 62

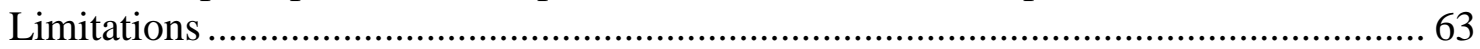

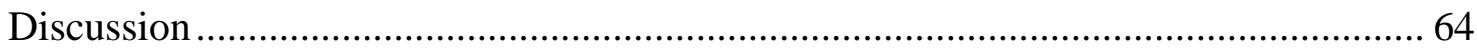

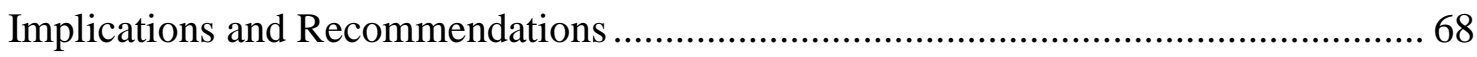

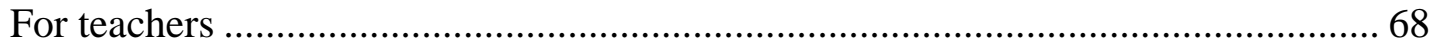

For TESOL training programs and ESL/EFL program administrators .................. 70

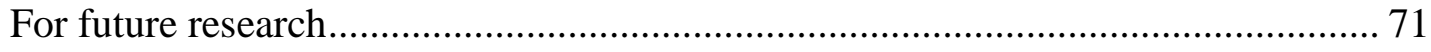

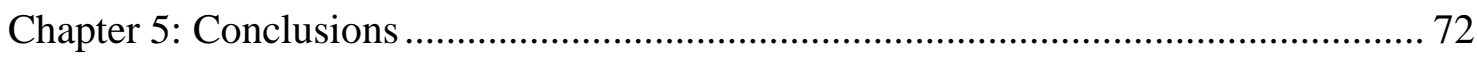

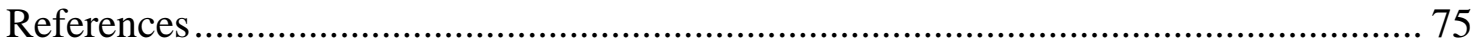

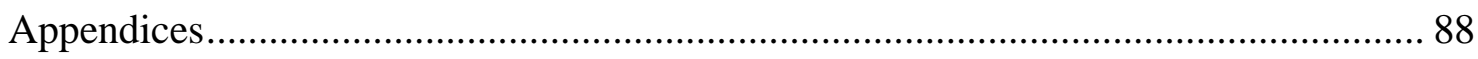

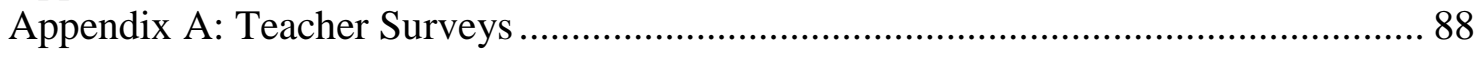

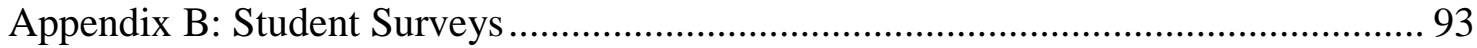

Appendix C: Invitation to Participate .................................................................. 98

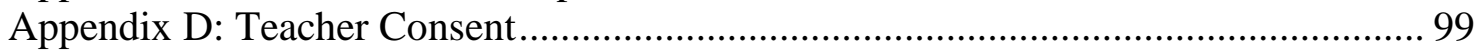

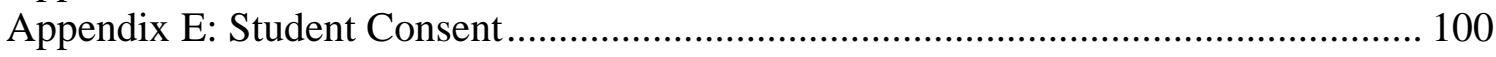




\section{List of Tables}

Table 1: Teacher Pre-and Post-Video Paired Questions................................................51

Table 2: Student Pre- and Post-Video Paired Questions ...............................................52

Table 3: Teacher Perceptions Regarding WE Instruction .........................................55

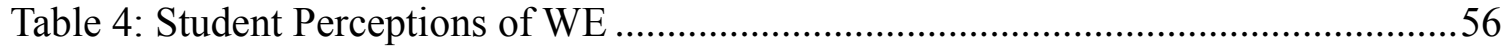




\section{List of Figures}

Figure 1: Interrelation of SSC and Perceptual Mismatches for Successful WE

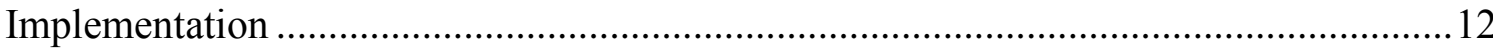




\section{Chapter 1}

\section{Introduction}

Pronunciation is perhaps the linguistics feature most open to judgment...One's accent easily evokes people's biases. For the same reason, pronunciation has been the most prescriptively taught aspect of language instruction.

(Canagarajah, 2005a, p. 365)

Pronunciation has always been one of the most difficult skills for students of a second or foreign language to master, and the belief that it's possible to achieve native or native-like pronunciation as long as learners commit reasonable time and effort to it (Marinova-Todd, Marshall, \& Snow, 2000) is rarely accurate. Regarding English Language Learning (ELL), in particular, it has been clear for some time that equating pronunciation outcomes to the sum of effort, time, and commitment is a misconception that ignored what may or may not be physiologically possible for students to achieve, as explained by the Critical Period Hypothesis $(\mathrm{CPH})$. The $\mathrm{CPH}$ suggests that it's nearly impossible to acquire native-like pronunciation in a second language (L2) when the onset of acquisition is past adolescence, or even earlier (Lenneberg, 1967, p. 176). That misconception was further supported by a long-held view in ELL that English from the United States or the UK represented the standard students should learn without regard to teaching context, student goals, teacher training, non-native English speaking teachers' (NNESTs) proficiency, the growing number of English accents (native and non-native); or other factors such as first language (L1), cultural background (C1), and the role of second language (L2) accent in student identity, all of which should be taken into account when designing ELL curricula. 
Over the years, progress has been made toward softening the long-held perception that Standard English (SE) pronunciation is superior to all other Englishes, but the field of TESOL still has a long way to go before non-standard $^{1}$ and native varieties have equal standing in the ELL classroom. TESOL has made some headway, for instance, in standing up against NNEST discrimination by "contesting discourses that privilege the native speaker" (Canagarajah, 2016, p. 9); however, this stance has been perceived by some applied linguists as nothing more than "a token gesture" (Widdowson, 1994, p. 389 ) and not commensurate with reality. Along similar lines, it is still common to find native English-speaking teacher (NEST)-only job postings at TESOL colleges and universities across the Unites States, where protections against overt discrimination of this kind is covered under Title VII of the Civil Rights Act of 1964. The situation for NNESTs is even more dire in OC and EC countries, where protections against discrimination are either not in place or, if they are, are circumvented to favor NESTs.

In light of the gap that exists between English as the highly diverse language it is today and the SE-only approach as it is taught in classrooms around the world, the present study approaches English pronunciation from the context of the World Englishes ${ }^{2}$

\footnotetext{
${ }^{1}$ for the sake of clarity, I will use the terms non-standard English, non-standard variety, or simply NSE to refer to all Englishes not spoken in one of the five countries where English is an L1; i.e., the United States, the United Kingdom, Australia, New Zealand, and Canada.

${ }^{2} \mathrm{WE}$ is used in this study as an umbrella term for Englishes taught in a variety of contexts and for a wide range of purposes. The present study will make no differentiation between WE and English as an International Language (EIL; as its name suggests, EIL is used primarily in international settings, whereas WE encompasses English spoken in all 3 Circle countries regardless of setting). English for Specific Purposes (ESP), English for Academic Purposes (EAP) and others that address specific segments of the ELL population are, for the purposes of the present study, considered subgroups within WE and will not be discussed. Only English as a Lingua Franca (ELF) and the Lingua Franca Core (LFC) will be briefly touched upon in the review of the literature.
} 
(WE; Kachru, 1985) paradigm, as it offers a more global and inclusive view of the English language. But before exploring the literature regarding WE and the factors that influence teacher and student perceptions regarding pronunciation instruction, it is important to appreciate the root causes of discrimination based on accent that is directed at ELLs and NNESTs as accented speakers of English. Some scholars have pointed out that accented speakers may face discrimination, in a majority of cases, due to nonlinguistic traits native English speakers (NESs) attribute to non-native English speakers (NNESs) due to prejudice and bias (e.g., Kubota, 2010; Kamisili \& Dugan, 1997). What follows is an overview of discrimination based on accent and of the onset of prejudice against "the other." Understanding that the root causes for prejudice against accented speakers of English is, in many cases, beyond the NNESs'/ELLs' control may lead English instructors and program administrators to incorporating WE into the curricula as a way to prepare ELLs to deal with such discriminatory practices.

\section{Discrimination Based on Accent}

One need not be a researcher to know people can be discriminated against if they speak accented English. When NESs interact with NNESs, the NESs' "natural ability $[\ldots]$ to overcome the problems of speech variability by adapting (or accommodating, or normalizing) their discourse to the linguistic, expressive or cultural characteristics inherent in their interlocutors' communicative performance" is often absent (Giles, Coupland \& Coupland, 1991). For this reason, communication breakdowns between NESs and NNESs may ultimately have little to do with faulty phonology and more with associations NESs make between their interlocutors' speech with perceived (real or 
otherwise) personal traits, educational background, legal status, and other factors, as will be discussed later.

To help visualize this failure to accommodate and normalize, recall the interaction between the Korean immigrant and the middle-class white man in the film Falling Down. The owner of the store is a middle-aged Korean man with a heavy accent, and he's reading a Korean newspaper:

Korean man: eighdy fie sen.

D-Fens: What?

Korean man: eighdy fie sen.

D-Fens: I can't understand you...I'm not paying eighty-five cents for a stinking soda. I'll give you a quarter. You give me seventy "fie" cents back for the phone... What is a fie? There's a "v" in the word. Fie-vuh. Don't they have "v's" in China?

Korean man: Not Chinese, I'm Korean.

D-Fens: Whatever. What difference does that make? You come over here and take my money and you don’t even have the grace to learn to speak my language... (Quoted in Kubota \& Ward, 2000, p. 81).

Michael Douglas' D-Fens' objections don't stem from the Korean man's failure to communicate (if so, he wouldn't have protested paying "eighty-five cents for a stinking soda"). Instead, D-Fens refuses to accommodate by feigning a communication breakdown ("I don't understand you") and failing to normalize the Korean man's speech for what it's lacking (“there's a 'v' in the word"). He concludes his tirade by claiming ownership over his (not the Korean man's) language, which he believes the Korean man didn't "even have the grace to learn to speak." 
Situations like D-Fens' and the Korean man's interaction are not at all uncommon. In fact, they are often part of the experience of speaking English with an accent, particularly in IC countries or in places where these speakers are a minority.

In order to explain the roots of discrimination based on accent, it is also helpful to learn when discrimination based on otherness begins and at what age. The following section on the onset of discrimination illustrates how children whose discriminatory behaviors against others are not corrected early in life may develop deep-seeded prejudices against people different from themselves as they age.

\section{Onset of Discrimination}

Researchers have found that children as young as 4 to 7 years of age can show bias against people different from themselves, with many Caucasian children showing signs of bias and/or discrimination by the age of 5 (Aboud, 2009). Lippi-Green (2011), a scholar on Disney films, pointed out that "children are systematically exposed to a standard language by means of linguistic stereotypes in film or television entertainment" (p. 101) that socializes them to believe there's a "right" and a "wrong" way to pronounce their first language. When not resolved early in life, biases can devolve into prejudice against accented speakers' regarding their place of origin, socioeconomic and immigrant status, and even attractiveness, intellectual ability, and character (Kamisili and Dugan, 1997). In a study with NES high school students enrolled in a class on WE accents, Kubota (2001) found that discrimination due to accent led to feelings of xenophobia, stereotyping, ethnocentrism, and avoidance of interactions with NNESs, particularly among students who already had at least somewhat negative feelings toward NNESs. Students who had the most positive views toward WE accents at the end of the semester 
were those who already had at least mildly positive perceptions of NNESs before the beginning of the class.

As previously stated, discrimination based on accent is ubiquitous and not likely to recede any time soon, despite heightened awareness (and acknowledgment) that it is, in fact, an issue with which students often have to wrestle. Nonetheless, teachers can contribute to lessening its effect by replacing their students' fears of being discriminated against because of their accent with agency to combat such discrimination. To do so, teachers may expose their students to other successful, accented English speakers through WE lessons. Honest conversations about accent, the role it plays (or doesn't play) in each individual student's identity/ies, and the options students have to change, modify, or eliminate accent altogether (when students feel accent is an issue) will lead to students self-reflecting into what it means to be a speaker of English.

\section{Personal Background and Motivation for This Study}

As a NNEST who was an ELL many years ago, I can attest to how much one's perspective regarding pronunciation teaching practices can evolve over time. As a student, I didn't question my teachers when told I had $a$ choice between American and British English pronunciations, and that I should stick with that choice until I fully modified my accent. My exposure to the language was limited to TV shows or movies, or to the occasional class-companion recording in flawless American or British accents. I never had a chance to develop an ear for other accents simply because I had never listened to them and, if I had (certainly not in class; maybe in movies or TV shows), I had no way or knowing how different or similar they were to what I heard in class. And I wish I had. 
Once I became a teacher, I followed in my former teachers' footsteps byimplicitly; I knew no other way-completely excluding WE varieties that depart from what is considered standard English (my approach at the time is consistent with the literature when it comes to novice teachers; we tend to mirror our teachers' until we develop our own teaching philosophy and style; e.g., Jusoh, Simun \& Chong, 2011). It wasn't until I moved to the US that I learned "American English" is not only not homogenous-from the waitress in Nashville, the African American boys playing hoops in the Midwest, the Metro riders in NYC, my coworkers in New Orleans, and many others-I also realized that TESOL has so vehemently excluded these purest expressions of real English from the ELL curricula, and it has been so effective at selling the case for SEonly classrooms, it might take many years before these accents can claim their rightful place in the students' ELL experience. The present study is an attempt to bring pronunciation instruction, and WE in particular, back to the forefront of the discussion of what should be included in the English Language Teaching (ELT) curricula.

I decided to focus solely on WE pronunciations because pronunciation is without a doubt the most salient of all the features of linguistic expression. Considering that nonstandard English accents are spoken by the vast majority of English speakers today, these pronunciations cannot continue to be excluded from the ELT curricula around the world to the detriment of the students who speak these accents. Further, this study will focus on adult students only because accented speech is present overwhelmingly in individuals who study English as their Second or Foreign Language past adolescence. While other aspects of WE such as writing, grammar, reading, etc., are not covered in this study, the results regarding teacher and student perceptions of WE can be useful for future research 
dealing with these topics.

My hope with the present study is that ELLs and NNESTs have a chance to learn that there is more to pronunciation than choosing between American or British English or, if they are lucky, a third native variety. I also hope that, through this study, teachers will broaden their teaching experience by incorporating WE into their practice and that this effort will, in turn, help their students became their best-informed, most empowered (accented or otherwise) English-speaking selves.

The following research questions helped guide the present study:

1. Are there any perceptual mismatches between the English varieties students want to learn and the varieties teachers want to teach, and do these perceptions differ depending on the learning context? and,

2. Does exposure to WE pronunciations change the students' and the teachers' perceptions of WE pronunciation varieties? 


\section{Chapter 2}

\section{Review of the Literature}

The following review of the literature is divided into two main sections. The first section covers the theoretical basis for this research through an overview of World Englishes and two concepts central to the success of WE in ELL: Student Centered Classrooms (SCCs) and Kumaravadivelu's Perceptual Mismatches (Kumaravadivelu, 2003). As will be seen in this section, student centeredness creates the ideal environment for the subsequent minimization or elimination of perceptual mismatches that often get in the way of teachers addressing their students' learning goals. It is, thus, important for teachers to understand the advantages of and become comfortable with SCC implementation before attempting to identify perceptual mismatches. Once perceptual mismatches are identified and, then, minimized, teachers can incorporate WE into the ELL curricula at every level of student competence and as much and as often as required per the periodic assessment of their students' needs. In sum, WE can only be successfully introduced into the ELT curricula if teachers commit to a Student Centered classroom and minimize, as much as possible, student-student and student-teacher perceptual mismatches.

As previously stated, non-standard English pronunciation is the most salient feature in the NNESs' language, and it is the focus within WE for the present study. The second section of this review deals with the existing literature regarding teacher and student perceptions of current pronunciation teaching practices as well as the student perspective regarding their own and their NNESTs' accents. The evolution of pronunciation instruction over the years and some materials useful to today English 
Language Teachers (ELTs) wishing to include WE into their curricula will also be discussed. Finally, a brief review of English as a Lingua Franca (ELF) and the Lingua Franca Core (LFC) are also reviewed in this section.

\section{Theoretical-Conceptual Basis for this Study}

The theoretical conceptual section of this literature review is made of two sections. The first section explores the supporting framework for the successful implementation of WE and includes the Student Centered curricula and an overview of Perceptual Mismatches. An explanation of the WE paradigm as the main theoretical basis for this study will follow in the second section.

\section{Supporting Framework for the Successful Incorporation of WE in the Classroom Student-centric vs. teacher-centric classrooms. \\ In order to learn how best to teach a language, teachers and theorists would do well to take into consideration the opinions of the people their theories are designed for: language learners}

(Madden and Moore, 1997, p. 15)

Not enough attention is paid to the wants, the needs, and the expectations of students about the content, the materials, or the methodologies used in the TESOL classroom (Kanno \& Applebaum, 1995). Student-centered curricula (SCC) increases the amount and the quality of WE-related learning outcomes by reconfiguring the roles and responsibilities teachers and students have in said outcomes (Cleveland-Innes \& Emes, 2005) as well as taking into account how the students' personal and professional goals relate to their acquisition of English. In the SCC the teacher is responsible for setting boundaries and for proposing the learning objectives, but the students have much greater 
input in the curriculum design than in the traditional, teacher-centered classroom. Cooperation based on the constant exchange of ideas about how to improve the learning experience between teachers and students (van Lier, 1995) involves collaborating to develop learning materials and activities, as well as negotiating how these activities are sequenced within the curriculum. In the SCC, this cooperation becomes the "cornerstone for curriculum design" (Nunan, 1986, p. 2) that is not limited to the beginning stages of the curriculum development, but takes place throughout a lesson or even a whole course. The student-centered curriculum has a set of common features, as described by Emes and Cleveland-Innes (2003, pp. 58-60):

- A clearly identifiable field of study.

- A defined interdisciplinary component.

- An international component.

- An experiential learning component relevant to program objectives.

- Provision for broad and extended faculty-student interaction at the program level.

- Integration of research.

- Explicit syllabus.

In addition, Nunan (1986) considered knowledge of the students' biographical data, previous learning experience, stage of linguistic development, and stage of cognitive development crucial to understanding who the teacher will be collaborating with. In the context of WE, understanding this information allows teachers to present WE pronunciations and related content in a manner that is commensurate with their students' stage of linguistic, cognitive, and overall EL development, which in turn will 
increase the likelihood teachers and students will engage in critical discussion about the place of WE in the students' overall English learning objectives.

\section{A student-centered classroom maximizes opportunities for learning WE}

perspectives that are facilitated by teachers, but where teachers and students are equally important in building said learning opportunities (Kumaravadivelu, 2003). Shifting from

Figure 1: Interrelation of SSC and Perceptual Mismatches for Successful WE implementation.

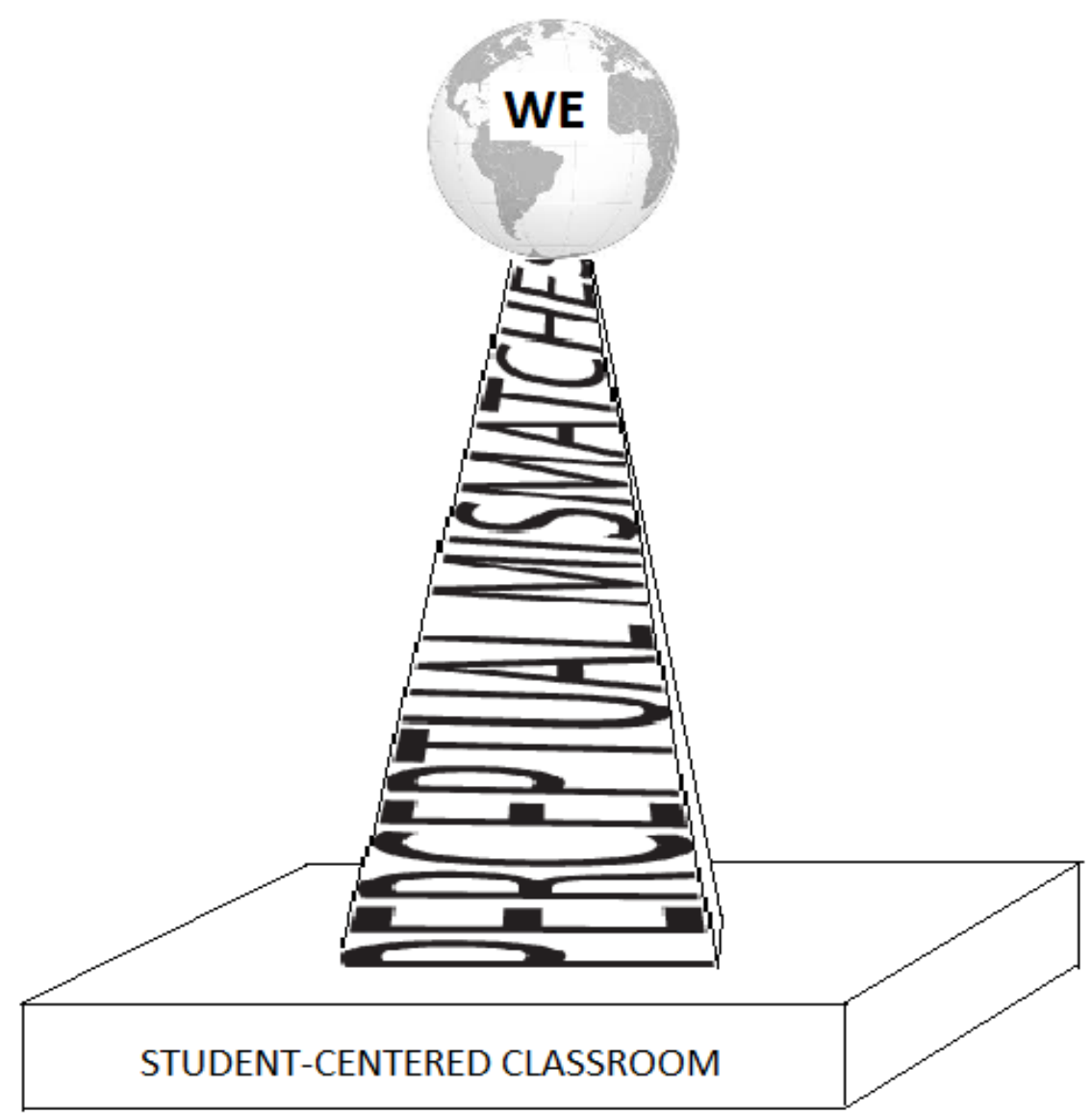

Figure 1: Illustration shows the interrelation between a solid Student-Centered structure for the unveiling of Perceptual Mismatches and subsequent WE implementation.

Figure 1 illustrates the interdependence of the student-centered classroom, perceptual mismatches, and WE paradigm. The depiction represents how relevant a solid student-centered curriculum is to the unveiling and minimization of perceptual mismatches. Once mismatches are identified and dealt with through a mechanism that includes periodic needs assessments and critical discussion (appropriate to the students' competence level), WE can begin to be incorporated into lesson materials and class discussion. 
a teacher-centered into a student-centered classroom is not a simple task, however. It requires teacher training to reduce or eliminate assumptions about the roles of teachers as the sole purveyors or knowledge. It also calls for teachers' understanding that studentcentered classrooms and student-driven curricula are not equivalent; that is, holistic learning and student-centered are not one and the same, for holistic learning merely refers to, but does not focus on the learner-centered aspect of curricula (Baxter-Magolda, 2000), while student centeredness does. This post-modern approach to ELT where learning context as well as culture are highly valued allows room for student input to shape outcomes that are "mediated by language, values, and social relationships" (Canagarajah, 2015, p. 13).

\section{Kumaravadivelu's perceptual mismatches.}

Only a concerted and cooperative effort on the part of the teacher and the learner will bring out the gap between teacher intentions and learner interpretations.

(Kumaravadivelu, 2003, p. 99)

Perceptual mismatches take place when teachers and students have different ideas of what constitutes a learning opportunity (Kumaravadivelu (2003). Eliminating or at least reducing perceptual mismatches increases opportunities for teachers and students to negotiate WE and WE-related learning outcomes (particularly when this approach is complemented by a learner-centered framework) that may not occur in the classroom otherwise. Kumaravadivelu identified ten sources for potential mismatches. They relate to cognitive, communicative, linguistic, pedagogic, strategic, cultural, evaluative, procedural, instructional, and attitudinal issues often present in the ELT classroom. Of particular importance to the present study are cognitive, communicative, pedagogic, 
cultural and attitudinal mismatches, as these are the most likely to hinder student-teacher and student-student interactions that lead to in depth reflection and critical discussion regarding the importance of WE to the students' learning outcomes.

\section{Cognitive mismatch.}

In much the same way teachers bring cognitive dimensions of their knowledge into the classrooms (Borg, 2003), ELLs also use "mental processes such as remembering, perceiving, recognizing, and inferencing" (Kumaravadivelu, 2003, p. 81) to make sense of the world around them. This understanding is learned, either consciously or subconsciously, through education, personal experience, or other means in and outside the classroom, and it plays an important role in how students perceive the intended WE learning outcomes during their interactions with teachers and other ELLs. Mismatches between teachers' and students' cognition arise from lack of prior knowledge and/or understanding of how each of the members in the ELT classroom processes the information shared throughout the learning process. Minimizing this mismatch may lead to better overall communication of explicitly or implicitly stated learning outcomes between all members of the classroom community.

\section{Communicative mismatch.}

It deals (mainly) with the oral communicative skills necessary for students and teachers to convey and process messages related to completing tasks and understanding course objectives. Especially in English as a Second Language (ESL) contexts, students in EL classrooms are already limited in their knowledge of the only language they (might) share with their teachers and fellow students. Taking the various stages of students' L2 communicative development into account and minimizing the effects of this 
limitation is important to the teaching and learning of WE-related topics, as introducing concepts that are too advanced for the students' linguistic competence may lead to misunderstanding and frustration that could limit or even eliminate opportunities for learning. On the other hand, introducing concepts using language that is below the ELLs' proficiency levels may be perceived as condescending and lead to similar, counterproductive outcomes.

\section{Pedagogical mismatch.}

Crucially important from the needs assessment stage and throughout the implementation of the learner-centered, WE-focused curriculum, pedagogic mismatch refers to conflicting perceptions teachers and students may have of the explicitly or implicitly stated learning objectives. Pedagogical mismatches regarding pronunciation outcomes have been particularly difficult to avoid because pronunciation and related topics are often learned implicitly or as a component in other courses such as listening/speaking or advanced communication. Minimizing or even eliminating this mismatch would mean making pronunciation outcomes explicit by bringing WE pronunciations and pronunciation intelligibility, a crucial but grossly overlooked factor of communicative competence (Litzenberg, 2014), to the forefront of teachers' and students' awareness.

\section{Cultural mismatch.}

A cultural mismatch arises when teachers' understandings of societal norms differ from their students' due to their cultural or ethnic backgrounds that often result in unmet, unstated, or misunderstood learning objectives. Cultural mismatches may occur particularly when teachers are not trained in intercultural awareness or to spot 
challenging situations stemming from cultural misunderstandings, or do not feel sufficiently comfortable dealing with these situations. It is, thus, important for teachers wishing to teach students from a wide range of cultural or ethnic backgrounds to receive the proper training and develop a proper understanding of what working with these populations entails.

For instance, students used to teacher-centered classrooms may not have the cultural know-how to give feedback on stated (or implicit) learning objectives that do not meet their learning goals. In a WE context, when teachers don't make it clear that higher student input is welcome and even encouraged, opportunities for critical discussions will be missed. When teachers state explicitly from the beginning that a student-centered learning environment exists, students from teacher-centered cultures may ease into a classroom with shared responsibilities more easily than if the approach were implied, thus clearing the path for new learning opportunities.

\section{Attitudinal mismatch.}

Perhaps one of the most important to this study, an attitudinal mismatch often results from other unresolved mismatches. Attitudinal mismatches refer to teachers' and students' affect with regard to what is being learned and what is being taught, as well as with the teacher-student dynamics of top-down (general rather than specific) and bottomup (focusing on individual components within the topic) teaching approaches. Negative student attitudes toward WE learning objectives (or methodologies, materials, etc.) that are not addressed in a timely way may lead to student apathy toward important WErelated topics, such as the diversity of the current Englishes landscape, the place of accent in student identity, intelligibility and its role in successful communication, and others. 
Understanding that perceptual mismatches are inevitable is as important as realizing that they are identifiable, thus manageable (Kumaravadivelu, 2003). Teachers who strive to evaluate classroom interactions, teaching outcomes, and even their own performance in an ongoing basis are much better prepared to deal with the repercussions or perceptual mismatches than are less reflexive practitioners. Minimizing these mismatches allows students and teachers to engage in healthy discussion, as much as the learning context and the students' proficiency levels allow, about WE content that may influence the students' intelligibility, pronunciation, and identity-related learning outcomes.

The preceding section provided an overview of the foundational elements for the successful implementation of WE in the ELL classroom: Student Centered Classrooms and (the minimization of) Perceptual Mismatches. The second part of the TheoreticalConceptual section of this literature review explains the features of WE and the reasons why it stands as the best approach for the teaching and learning of spoken-English topics in today's ELL classroom.

\section{Englishes around the world.}

My use of "Englishes"(...) introduces a vital concept of pluralism, of linguistic heterogeneity, of cultural diversity, and of dramatically different theoretical and methodological foundations for teaching and research in English

(Kachru, 1984, p. 26)

Crystal (2008) estimates that there may be as few as 700 million and as many as 2 to 3 billion speakers of English, or about one third the total world's population. The more conservative estimates exclude speakers from India (believed to be around 700 million), 
and about 20 or so million people who are taking EL classes any given year around the world. With as overwhelming a growth in the number of speakers and the varieties of English spoken, there have been several attempts to categorize and account for these new varieties over the years; e.g., Görlach’s Circle Model of English (Görlach, 1988); Graddol, 2006; and Modiano's Model of English (Modiano, 1999), as cited in Jenkins (2009); Haugen, 1966; and Sung-Yul and Wee, 2009. Also, Schneider's Dynamic Model of Postcolonial Englishes (Kirkpatrick, 2007), Streven's World Map of English (Strevens, 1980), and McArthur's Circle of World English (McArthur, 1987), among others. All these models have encouraged discussion about the innovations in the language and the contexts where these new Englishes are spoken. However, it was Kachru's (1985) Three Concentric Circle Model of the global spread of English, also known as World Englishes, that has provided the best framework to date for the understanding of these new pronunciation varieties and the implementation of these New Englishes into ELL curricula.

\section{Kachru's World Englishes paradigm.}

The WE paradigm is a "framework of knowledge that accords as much importance to the socio-political context and human needs of its users as to the attributes of the language itself" (Brown, 1997, p. 137 as cited in Brown, 2001, p. 372). Through this framework, Kachru challenged the long-held supremacy of native-speakerism for teaching and learning English by creating a model that accounted for all "ESL and EFL contexts around the world" (Kachru, 1984, p. 26) that included all the new territorial domains and cultures where English is increasingly being spoken. In a WE paradigm, three key elements are believed to exist (Kachru, 1988 as cited in Brown, 1993): 
A "repertoire of models for English".

"The localized innovations [in English] have pragmatic bases".

"The English language now belongs to all those who use it" (p. 59).

This last element, the notion that English belongs to everyone who uses it, departs from the long-held assumption that English belongs to a minority of native speakers; instead, it assumes that English belongs to all those who speak it at home, in school, or in business, and even to those who make it their own through innovations typical of any language shaped from within (i.e., endo-normatively) rather than by outside forces (i.e., exo-normatively; Widdowson, 1994). The first two points can be explained in the context of the organization of all these new varieties of English, emerging and native, as well as the variation that exists within each that are categorized into the Circles explained below. Kachru termed these three circles the Inner Circle (IC), the Outer (or Extended) Circle (OC), and the Expanding Circle (EC) of World Englishes.

\section{The inner circle.}

The Inner Circle (IC) includes the countries where English is spoken as a "native" or primary language; i.e., the United Kingdom, the United States, Canada, Australia, and New Zealand. English from these countries is thought to be norm-providing because it is native speaker (NS) norms which are used in a majority of EL teaching programs around the world (though, interestingly, NS norms are overwhelmingly based on US and UK English varieties only, excluding all others). In 1992, the number of Inner Circle speakers was estimated to be around 350 million (Jenkins, 2009). Although this number will rise in keeping with world population growth, IC speakers are a shrinking proportion of English speakers (Deterding \& Kirkpatrick, 2006) as Outer Circle and Expanding 
Circle English speakers continue to multiply exponentially.

It is important to note that the confusion that resulted from this "new" classification of Englishes prompted TESOL scholars such as Jenkins (2009) to emphasize "inner" did not mean "superior." Also, Canagarajah (2005b) pointed out the Inner Circle denomination was meant to be a descriptive rather than prescriptive, i.e., never meant to point out what "should be" but "what is".

\section{The outer circle.}

The Outer Circle (OC) is made of countries where English is spoken as an institutionalized variety and as a result of colonization during the earlier stages of the spread of English. These countries are usually culturally and linguistically diverse, whereby English: 1) is only one of the languages spoken-although it is occasionally spoken by some in the OC as their first, often their only, language (Jenkins, 2009)-; and, 2) has a solidified status in most of these countries (thus the term "institutionalized"). OC Englishes are spoken in countries such as Singapore, Zambia, Nigeria and India and their varieties are thought to be norm-developing, as they are believed to be transitioning from the native standards implemented at first, to new standards applicable to the actual varieties that have evolved over time (endo-normatively) in those territories. In fact, Kachru (1990) observed that OC English speakers in India, for example, had already begun to accept and even prefer their local varieties over Received Pronunciation (RP) in as early as the 1980 s. Functionally, Outer Circle varieties were often used as non-native varieties in official capacities such as in schools and other public entities but are now considered "nativized" dialects that have expanded in both "range" and "depth" within the larger societal, educational and literary domains (Kachru, 1985). For these reasons, 
competence in English is often seen as a symbol of higher educational and socioeconomic status within OC countries.

\section{The expanding circle.}

In the Expanding Circle (EC), Kachru argued, English has achieved International Language (IL) status in countries where colonization of English speaking settlers may or may not have taken place. EC speakers learn what has traditionally been known as English as a Foreign Language (EFL), as these speakers are surrounded by their native language outside the classroom. These varieties are thought to be norm-dependent, as they have historically relied on IC countries to provide the standards upon which English teaching and learning is based. More recently, however, in EC countries in Asia, South America and Europe English is no longer used "for extra community relations alone" (Canagarajah, 2005b, p. 23) and has become even less dependent on IC norms than when Kachru first introduced the term (Jenkins, 2006; Seidlhofer, 2004). Examples of EC countries include China, Greece, Brazil, Japan, Russia, and all those where English has not been institutionalized and is not spoken as an L1.

\section{Observations to the three circle model.}

In recent years, researchers and scholars have pointed out "flaws" in the WE model and have attempted to re-contextualize how the term is used or even replace it altogether. Sifakis (2004) recycled Kachru's model by placing all three circles along a continuum where she illustrated the variability between and within circles: IC on the norm-bound (N-bound) end where countries share "regularity, codification and standardness" features; and "communication, comprehensibility (and) culture" (C-bound) EC countries on the other, learned behavioral-perceptual end, with OC countries 
somewhere in between both ends of the spectrum (p. 239). Yano (2001) predicted Kachru's model would experience changes in years to come as ESL speakers achieved "functional nativeness" (p. 122) that would blur the lines between IC and OC Englishes. Michieka (2009) showed the permeability of the Circles' boundaries in a study about Expanding Circle English in rural areas of the Outer Circle country of Kenya, where Kisii is the L1. And Davydova (2012) argued that it is already possible to make generalizations between indigenized (OC) and learner (EC) English varieties of similar sociocultural backgrounds in the context of Second Language Acquisition (SLA) theory. Her study on Indian English and English spoken in Russia led her to conclude that EC Englishes are "self-contained forms of English that reflect order and structure within the grammar and need to be documented and studied systematically in analogy to indigenized forms of English" (p. 366).

Despite perceived issues or needed improvements to the Three Circle Model, a WE context that includes all speakers of English, whether in a continuum and with permeable boundaries between its members or with clearly delineated borders between OC and EC speakers, the WE model continues to provide the most comprehensive way to account for all English varieties spoken today.

\section{Shifting paradigms.}

In order for the professional field of TESOL to move away from the NES model and into the more inclusive WE model (which more accurately depicts current English usage around the world), there needs to be an overt effort on the part of TESOL scholars, program administrators, student-teachers, and practicing ELTs toward a student-centered approach that promotes critical thinking about emerging English varieties in all levels of 
ELL proficiency. As explained in Brown (1993), it is not enough for pre-service teachers to know about WE. First, ELTs need to understand their own biases and preconceptions about WE as a field of study, about who is a speaker of English (Baxter, 1980), and about their vision for their teaching practice. During pre-service training, it is important for student-teachers to seek opportunities to enrich their knowledge of WE via WE courses, class discussion, group work, and other venues such as existing research available through academic journals. And if student-teachers are to seek opportunities to enhance their future practice through their understanding of WE, it follows that TESOL training programs should make more WE-related content (that is negotiated with TESOL faculty) available to TESOL students. After such an improvement has been made, TESOL instructors need to implement WE knowledge explicitly by infusing their lessons with activities that promote student-teacher awareness of the topic which will, in turn, further develop their competencies, uncover issues with regard to WE, and clarify the place of WE within their future practice. As Brown put it, shifting paradigms is not easy. Change can take place, however, if teachers, program administrators, student teachers, and TESOL scholars all do their part to promote WE from their respective areas of expertise. Having explored the first, theoretical-conceptual section of this literature review, the second and final section will deal with the factors that influence the perceptions and attitudes teachers and students have surrounding pronunciation instruction and learning. An overview of English pronunciation instruction and materials, as well as a brief introduction to ELF and LFC are also included.

\section{Perceptions and Attitudes}

Dalton-Puffer, Kaltenboeck, and Smit (1997) defined attitudes as "the mental 
constructs acquired through experience, predisposing a person to certain feelings and reactions in response to certain situations, persons or objects" (p. 116). As it concerns spoken language, attitudes are "any affective, cognitive or behavioural index of evaluative reactions toward different language varieties or their speakers" (Ryan, Giles, \& Sebastian, 1982, as cited in Litzenber, 214, p. 3). According to the Oxford English Dictionary (OED), a perception (as a count noun) is "5.b. An intuitive insight; an understanding. Also: an interpretation or impression based upon such understanding; an opinion or belief" (2005). In this context, the following pages explore the literature on learner and teacher perceptions and attitudes around pronunciation instruction, which provided the backdrop for the present study.

\section{ELT attitudes and perceptions.}

Good teaching cannot be reduced to technique; good teaching comes from the identity and integrity of the teacher.

(italics in the original; Palmer, 2007, p.10)

\section{Factors that influence ELTs' perceptions and attitudes about their practice.}

Personal factors that influence teacher attitudes and perceptions

Teacher practices are influenced by the practitioners' personal and professional experiences in and outside the classroom. Personal factors that affect how teachers develop their practice include the personal goals, values and belief systems they bring with them prior to, during, and after teacher training (Richards, Tung, \& Ng, 1992); their age (Libben \& Rossman-Benjamin, 1992); the presence or absence of support systems, especially during the earlier years of their practice (Brannan \& Bleistein, 2012); and their life experiences (Borg, 2003; Golombek, 1998; Libben \& Rossman-Benjamin, 1992. 
Richards, 1996). Intangibles such as time limitations (Baker, 2011) and motivation (Jusoh et al., 2011); teacher attitudes toward the subjects they teach (Golombek, 1998; Whitaker, Whitaker, \& Lumpa, 2009); and even the teachers' experiences as learners themselves (Borg, 2003; Libben \& Rossman-Benjamin, 1992) were also found to influence the procedures and contents teachers use in their classes.

Besides relying on personal-affective traits to define their practice, teachers also tend to look for the support from family, friends, and their mentors (Brannan \& Bleinstein, 2012). In their study with Canadian TESL (Teachers of English as a Second Language) teachers, Libben and Rossman-Benjamin found that pre-service ESL teachers' classroom activities were highly correlated to the student-teachers' TESL instructors' methodological views, even though the same student teachers surveyed believed that these activities should be determined individually by each of them. The researchers also found that even though novice teachers were generally less inclined to use progressive approaches than seasoned teachers, possibly due to their lack of experience (Jusoh et al., 2011), they also seemed more likely to look for advice than did their more seasoned counterparts. The authors concluded that ELTs and their trainers are influenced by the "cultural norms and values" (p. 9) each member of the TESOL community, where teachers borrow and adopt (and often adapt) ideas from one another, contributes to it.

\section{Cognition and teachers'maxims.}

As TESOL instructors' influence over their students wanes over time, the novice teachers' own points of view begin to be reflected in the teaching maxims, or "the wisdom of practice itself" (Shulman, 1987, p. 11), teachers apply to different aspects of their practice (Borg, 2003, p. 86). These maxims result from teacher cognition, or the knowledge, 
thoughts and beliefs acquired from a combination of the teacher's cultural background and beliefs systems, their accumulated experience (Richards, 1996), and their professional development. In a study with ESL teachers in the United States, Golombek (1998) found that teachers' moral and affective personality traits had the greatest impact on their teaching maxims. She found that teachers used these traits as the filter to assess how effectively they incorporated the teaching strategies they learned during TESOL training as well as how they reacted to challenging situations in the classroom. That is, these teachers' preconceptions for outcomes based on moral or personal bias influenced their practice more so than their TESOL training. Similarly, in a study with OC teachers in Hong Kong, Richards et al. (1992) concluded that teachers' cognition (as well as their TESOL training) affected both positively and negatively the learning outcomes they perceived their students needed to achieve. ${ }^{3}$

\section{Professional training and teaching experience.}

TESOL training and teaching experience was also found to impact what teachers do in the classroom (Borg, 2003; Golombek, 1998; Libben \& Rossman-Benjamin, 1992; Richards, 1996). Jusoh et al. (2011), for instance, found that novice Malaysian teachers felt ill-prepared for the challenges they encountered in the ELT classroom after graduation, especially as it concerned interpersonal relations, and that these teachers believed continued professional development was important to close the gap between

\footnotetext{
${ }^{3}$ It is worthwhile noting that even though cognition is recognized as an important area of study toward understanding teacher attitudes, virtually no research has focused on cognition regarding pronunciation instruction, WE, ELF/EIL, or related topics, as per Borg's metaanalysis of ESL and EFL teaching cognition studies from 1976 to 2001. Lack of research in this area may be a contributing factor to the decline in pronunciation instruction and the absence of explicit WE in the curricula so many years after being first introduced.
} 
their training and their actual teaching preparedness. The authors concluded that the root cause for this mismatch was how improperly institutions of higher learning prepared teachers for employment in the real world, and called for better assessment of the employment and educational needs MA TESOL students will have upon graduation. Jusoh's findings are similar to Ochsner's (1980) study thirty years earlier on the perceptions of novice as well as experienced (US) MA TESOL graduates with regard to their training. Ochsner found that a majority of US graduates rated their training less favorably than teachers who had overseas experience in terms of bilingual education and SLA, due in part to the higher exposure to multicultural issues teachers working overseas had to deal with compared to ESL teachers with no overseas experience.

Other elements that affect teacher practices as well as the development of the teaching materials they will use in the ELT classroom are the teachers' professional goals (Richards et al., 1992); how they thought they fared in the classroom and how that competence interrelates with their own personal identities (Steinbach \& Kazarloga, 2014); the professional development opportunities they have beyond their formative years (Baker, 2011; Jusoh et al., 2011); the role of program administrators (Kang, 2015); and other factors beyond the teachers' control such as education policies at the local and country levels, as well as their perceptions of these policies and how to implement them (Cray, 1997; Kang, 2015).

Attitudes developed over time result in the feelings and thoughts teachers display regarding their own and other people's accents, and these attitudes affect how teachers address pronunciation-related challenges in the classroom (Dyers \& Abongdia, 2010). As stated in the previous section, teachers may lean toward a specific teaching approach 
based on a combination of learned and experienced factors. In the case of pronunciation instruction, these factors will affect how teachers perceive the ever evolving concepts of WE, ELF, English as an International Language (EIL), and other approaches to ELT and learning based on non-native speaker models that have been relatively absent from EL classrooms. In this context, the following section focuses on teacher attitudes and perceptions specific to the teaching of English pronunciation and TESOL training (or lack thereof) in the specific area of WE.

\section{Contributing factors to teacher attitudes regarding WE and pronunciation} instruction.

Research has found that teachers have generally positive attitudes toward pronunciation instruction (though experienced teachers view it more positively than novice teachers (Richards et al., 1992)). Despite this, few TESOL practitioners are trained in English phonology (Breitkreutz, Derwing, \& Rossiter, 2001; Derwing \& Munro, 2005) and even fewer in pronunciation pedagogy (Murphy, 1997). As Derwing and Munro pointed out, there is often extensive training on methodologies and other pedagogical aspects of teaching, but when it comes to pronunciation instruction, teachers are usually left to their own devices.

\section{Decline in pronunciation instruction.}

Pronunciation instruction has been all but absent from TESOL curricula and the ELT classrooms in recent decades, and two factors are believed to be the main contributors to this decline: the Critical Period Hypothesis $(\mathrm{CPH})$ and the Communicative Language Teaching (CLT) approach. The $\mathrm{CPH}$ argues that there is a biological component that makes it nearly impossible for an L2 learner to sound native-like when 
the onset of pronunciation acquisition is past puberty, sometimes even earlier (Lenneberg, 1967). Once this hypothesis, which came about on the heels of the audiolingualism era, made its way to Second Language Acquisition (SLA) and TESOL circles, it became harder for teachers to continue focusing on pronunciation instruction. In addition, the CLT's "input based instruction and [the] perception that pronunciation issues were related more to accuracy than communication" (Breitkreutz et al., 2001, p. 52) further discouraged pronunciation from being included in ELT curricula (Breitkreutz et al., 2001; Derwing \& Rossiter, 2002; Madden \& Moore, 1997), making it virtually impossible for teachers to continue teaching pronunciation while focusing on oral competence (Nunan, 1986). Further, pronunciation learning requires explicit instruction where knowledge and skills specific to what and how to teach are needed in order for the instruction to be effective (Derwing \& Munro, 2009; Derwing, 2003; Morley, 1991), and the CLT inherently neglects teacher competence on any approach to pronunciation instruction (Seidholfer, 1999).

\section{Lack of inter/multicultural training and awareness.}

In much the same way as pronunciation pedagogy has been overlooked in the TESOL curricula, teacher training on diversity-related topics — a crucial initial step toward a thorough understanding of WE-, has also been insufficient in all 3 Circles of WE. Multicultural awareness and competence, as noted in the Perceptual Mismatches section of this literature review, is central to the minimization of mismatches and the proper implementation of WE pronunciations in the ELT classroom. As noted by Johnson (1995), student-teachers first need to become aware of their own preconceptions about culture if they are to develop the empathy needed to understand their students' 
beliefs. To this end, TESOL training should include multicultural awareness courses and exercises that prepares student-teachers in dealing with issues of this kind once they graduate (Faez \& Valeo, 2012). Unfortunately, WE and related courses are seldom mandatory in TESOL curricula, and this results in only a fraction of TESOL graduates receiving training in culture-related subjects during their MA or Certificate in TESOL studies (Nelson, 1998). According to the Directory of Teacher Education Programs in TESOL in the United States and Canada (2004), around 180 colleges and universities offer MA, MS, or TESOL-concentration degrees in these two countries. Of this number, less than half ( 75 schools) offer at least one class related to language and culture, intercultural communication, diversity, or cross/multicultural issues in ESL. Even fewer (8; less than .5\%), offer a course in World Englishes (3), English as an International Language (2), Language Variation (2), or The Global Spread of English (1), despite empirical evidence that student-teachers who learn about these perspectives during TESOL training have the potential to become more reflexive and inter-culturally aware TESOL practitioners (Brown, 2003; Brown, 2002; Sakai and D'Angelo, 2005). In this context, it follows that teachers who are trained in culture and diversity-related issues (and believe understanding of these topics is important to healthy classroom environments) may become more open to using alternative perspectives such as WE pronunciations within a student-centered environment than teachers who are not trained in these topics. Increasing training in these areas would prevent graduates from facing issues related to diversity, culture, or WE for the first time in the classroom, a situation that is hardly ideal in today's already diverse ELT contexts.

\section{Teacher preference for the nativeness model.}


Regardless of the quality or quantity of pronunciation instructions, WE training, or of no WE training at all, TESOL professionals still have to decide what English dialect/s they will teach (Dauer, 2012), and whether or not they will expose their students to WE culture in addition to or instead of IC culture (Farrell and Martin, 2009). When it comes to English pronunciation instruction, in particular, there are two distinctly opposite principles in SLA: The nativeness principle, and the intelligibility principle ${ }^{4}$.

The nativeness and the intelligibility principles.

The nativeness principle, the dominant pronunciation-teaching approach during the height of the audiolingualism era of ELT in the 1950s, predicates that achieving native-like competence is the most desirable outcome of pronunciation instruction (Levis, 2005) despite no empirical evidence to indicate such an outcome is achievable through classroom instruction (Derwing \& Munro, 2005). Conversely, the intelligibility principle acknowledges that communication can be highly successful even in the presence of strong accents, for correlation between accent and comprehensibility has never been found (Derwing, Munro, \& Wiebe, 1998). The nativeness principle is further challenged by Critical Pedagogy (CP) theorists who posit the question of who is being "advantaged and who is being disadvantaged when NES styles of speech serve as the sole models and goals of pronunciation teaching” (Murphy, 2013, p. 260). In this sense, Matsuda

\footnotetext{
${ }^{4}$ Matsuda and Friedrich, 2012, p. 17, in fact argue that in the EC there are three possible choices: An international variety of English, the speakers' own variety of English, and an established variety of English. For the purposes of this study, only the two categories described above are studied as the speakers' own and/or the international varieties of English could fall under the intelligibility perspective. Similarly, the established variety of English would fit into the nativeness/standard English category. A dichotomous approach makes it possible to streamline student options keeping in mind an intelligibility approach could be expanded into other subcategories.
} 
and Friedrich assert that the selection of English variety to be used in the classroom must carefully consider the learning context, future interlocutors with whom students will interact, student expected outcomes, student input, etc., while also making sure students are aware that the variety/ies chosen is/are just one/several of many and not, by any means, the correct one/s.

A Québec study with NNESTs (Steinbach \& Kazarloga, 2014) illustrates the disconnect that sometimes exists between highly intelligible NNESs pronunciations and the speakers' own measure of success in the language. In the study, an overwhelming majority of teacher participants (94\%) expressed satisfaction with their accents, but half (55\%) also said that they would acquire native-like pronunciation if they could. These teachers believed having native-like pronunciation would make them sound more "professional" (p. 327), a belief that was tied to "their perceptions of their own cultural identities and how they [saw] their role as future teachers of ESL" (p. 326).

Another unintended consequence of teaching NS pronunciation standards, both for native and non-native teachers who lack the proper training, is that they set unattainable goals for themselves and for their students (e.g. Derwing, 2003; Jenkins, 2002). NESTs could not (and should not) be assumed to be inherently equipped to teach pronunciation, as fluency does not necessarily translate into a teacher's ability to meet the students' intelligibility needs as they pertain to content, materials, or methodology (Breshears, 2004; Seidlhofer, 1999). Similarly, NNES instructors are more often than not inherently ill-prepared to teach a Standard English phonology in which they themselves are rarely proficient (Breitkreutz et al., 2001). It follows that it is unreasonable to expect NESTs or NNESTs alike to teach concepts or use methodologies for pronunciation 
instruction they don't fully understand.

For these reasons, it is important that teachers be familiar with the concepts of intelligibility, comprehensibility, and accent as a means to complement a student-centered approach to WE, as knowledge of these concepts may aid in addressing student communication needs regardless of the teachers' phonology or pronunciation teaching training.

Intelligibility, Comprehensibility and Accent.

In order for teachers to be able to focus on intelligibility over nativeness (or nativeness over intelligibility, as determined by their students' needs assessments), teachers need to know what the concepts of intelligibility, comprehensibility and accentedness mean, how they differ from one another, and what their application into classroom tasks entails. Derwing (2010) provides a working definition for each:

Intelligibility refers to the "degree to which (a listener) understands a NNES;" "comprehensibility is a judgment of how easy or difficult an individual's pronunciation is to understand;" and, "accentedness is a judgment of how much one's speech differs phonologically from the local variety." (p. 29).

Teachers' understanding that the degree of comprehensibility of their students' accent is beyond their students' control may lead to a stronger focus on intelligibility, or the degree of speech production their students may actually be able control (depending on several elements, as will be seen in the next section on the factors that influence student acquisition of the L2 phonology), on a student-by-student basis. An intelligibilityfocused approach will also allow teachers to aid students who do not wish to acquire 
native-like pronunciation on strategies to repair their speech when communication breakdowns occur. In addition to the above strategies, teachers may expose students who wish to acquire native-like pronunciation to phonology-driven exercises that, through repetition and a strong emphasis on accuracy, may lead their students to achieve their pronunciation goals.

Although the nativeness vs intelligibility dichotomy has been around for decades, research on pronunciation teaching practices has found that a vast majority of ESL and EFL teachers continue to implement some version of the nativeness model (Jenkins, 2005; Sifakis \& Sougari, 2005; Sifakis, 2004) as needed (a majority of teachers use this approach on a student-by-student basis, as few ELT programs offer conversation courses nowadays) despite 8 out of 10 English-language instructors in the world are non-native English speakers (Canagarajah, 2005b), and that a similar percentage of ELL interactions in English occur with other ELLs or NNESs (Jenkins, 2005; Gnutzmann, 2000). Teachers who favor the nativeness approach often fail to consider intelligibility as a legitimate pronunciation outcome (Litzenberg, 2014) precisely because many of them are not familiar with the constructs of accent, intelligibility and comprehensibility that may lead to higher appreciation of the interplay between student accent and identity, for example.

Having explored the reason why teachers lean a specific way with regard to their teaching practice in general and the teaching of English pronunciation, in particular, the following section addresses the factors that contribute to student pronunciation acquisition as well as their perceptions and attitudes regarding their own and their NNESTs accents. 


\section{Students' perceptions and attitudes toward EL pronunciation.}

You must be familiar with different accents (...) because you are communicating with the world, not just to the American, English speaking world.

(A student in Baccaglini's, 2012, study.)

\section{Factors that influence English L2 phonology attainment in students.}

Studies on the reasons students are intrinsically motivated to modify or improve their L2 pronunciation, due to personal or cultural factors; or extrinsically motivated, due to environmental/contextual elements show conflicting accounts on the factors that affect L2 phonology acquisition. Among the most important intrinsic factors is motivation. Marinova-Todd et al. (2000) believed that motivation and the overall learning environment were more important than age of acquisition to attain English L2 phonology. However, Dalton-Puffer et al. (1997) found that motivation alone did not always result in the acquisition of L2 phonology, and LoCastro (2001) concluded that a desire to speak like a native speaker was not the main source of such motivation as, contrary to teacher perception, there was "little empirical support for the assumption that L2 learners seek to achieve native-like competence" (p. 71) in the first place.

ELLs' life experiences and those that helped shape their personal and cultural identities were also found to impact their pronunciation learning outcomes (Kanno \& Applebaum, 1995). In this regard, the literature points to accent modification as largely dependent on student L1. In a study with Mandarin and Slavic L1 students, Derwing, Munro, and Thomson (2007) concluded that Slavic students were better able to improve both their fluency and their intelligibility to resemble native L2 phonology than Mandarin L1 students. However, the study focused on NESs' comprehensibility assessments of 
these students' speech and didn't take into account the type and length (or lack) of instruction, materials used, or the instructional context that may have contributed to this difference. Other studies have found L1 may negatively influence English L2 phonological acquisition but only when considered in conjunction with length of residence in the L2 country as well as aptitude for learning L2 accents (LoCastro, 2001; Levis, 2005; Gatbonton, 2000).

\section{Student perceptions of NNES accent with regard to pronunciation instruction.}

ESL students communicate with NESs as well as other NNESs (Rossiter, 2009), and most ELLs in OC and EC countries communicate almost exclusively with other NNESs (Schaetzel \& Ling, 2009; Sifakis, 2004). Despite this and the fact most ELTs are also NNESs (Brutt-Griffler, 2002; Canagarajah, 2005b; Seidlhofer, 2001), and often illprepared to teach an English phonology they are not familiar with (Breitkreutz et al. 2001), the nativeness model is still preferred by a majority of ELLs. Kang (2015) found that students in all three Circles of WE preferred NS pronunciation models despite the fact that most of their teachers were NNESs. In a separate study on student perceptions in the EC countries of Japan and South Korea and the OC country of Malaysia, Tokumoto and Shibata (2011) found that many students rejected their L2 accents due, in part, to a preponderance of the nativeness approach in these countries. The authors also found that the Japanese students felt the most negative about their own intelligibility regardless of interlocutor (NESs or NNESs) and that the Malaysian students had the best perceptions of their own accents, followed by the South Koreans. Additionally, the Malaysian students were the least likely to aim for native-like pronunciation, as they felt their accented speech was comprehensible to the majority of interlocutors (i.e., the Malaysian 
students were used to being understood and their interlocutors were used to the Malaysian students' accents). In this study, the Japanese students were the most likely to aim for native-like pronunciation. The Malaysian students, on the other hand, based their attitudes on actual experience with "mutual accommodation" (Seidlhofer, 2001, p. 147) of their and their interlocutors' speech, an advantage the Japanese and Korean students did not have. Tokumoto and Shibata concluded that Japanese and Korean students' “judgments could not be based on their actual experience of successful or unsuccessful communication in English but on their belief built upon language ideology in the society" (p. 403), which highlights the strong influence the nativeness model of pronunciation instruction still has over ELLs around the world despite de advent of globalization and the Internet.

Similar findings to those in Tokumoto and Shibata's study regarding student negative perceptions of accent can be found in Hertel and Sunderman (2009), Derwing (2003), Madden and Moore (1997), and Derwing and Munro (2009), and others. Madden and Moore, for instance, found that more than half of the students they surveyed defined "good pronunciation" as sounding like a native speaker. A study with Japanese students at the Department of World Englishes at Chukyo University in Japan, where students are required to take an Introduction to Studies of World Englishes and a Singapore Seminar in the OC country of Singapore, showed that exposure to various English dialects was not enough to rid students of misconceptions about WE accents. Even though the course helped students better understand WE, at the end of the term they still showed "stronger preference for traditional English varieties and [even] lower tolerance of New Englishes" (Yoshikawa, 2005, p. 360). Similarly, Derwing and Munro found that ESL students' 
preference for NS models was usually tied to the perception, among others, that they would earn the respect of NESs for speaking "well" (p. 547; a perception shared by some NNESTs in the study by Steinbach \& Kazarloga (2014) who believed they would be considered more "professional" if they spoke with a NES accent). An interesting finding in this study was that almost none of the International Students (IE) in that group expressed dissatisfaction with their accents, whereas only one in four of ESL students said they were satisfied with theirs. In line with Tokumoto and Shibata's findings, students in this study who were exposed to a wider variety of accents were usually more accepting of accent as a normal occurrence. A study by Bayyurt and Altinmakas (2012) further supports a possible link between length of exposure with acceptance of WE. Through their Oral Communication Skills in English course based on WE and EIL principles, Bayyurt and Altinmakas found that their Turkish students enjoyed learning about the different pronunciations of English, that English is the official language in some countries in Africa and Asia, and using materials that highlighted WE, among other positive results. All these examples show that, as pointed out by Kelch and SantanaWilliamson (2002), wide-ranging perceptions of accent such as the ones expressed by the students in these studies may suggest that the more students are exposed to OC and EC accents, the better they will perceive their own and other NNES accents.

\section{Literature regarding student self-perceptions of accent.}

Excluding WE accents from the ELT curricula has certainly not helped spearhead research in the area of ELLs' perceptions regarding the issues that impede their own intelligibility. Studies on this topic have been largely ignored (Steinbach \& Kazarloga, 2014), mainly because a vast majority of researchers don't consider empirical, self- 
awareness reports of accent reliable enough for such findings to be implemented in the classroom (Dlaska \& Krekeler, 2008). As a result, research on NNES accent has primarily focused on NES comprehensibility assessments of NNESs' accents, and this research represents the bulk of what informs materials development and pronunciation instruction practices (Derwing \& Munro, 1997; Flege, 1988; Kraut \& Wulff, 2013; Kubota, 2001; \& Murphy, 2013).

\section{Student perceptions of NNESTs.}

Research in the area of ELLs perception of NNESTs' accents is still very limited compared to other areas of teacher competence (Sifakis \& Sougari, 2005). However, what little we do know reveals that student perceptions of their NNESTs ability to teach EFL and ESL can be negative at times, even though ELLs are taught mainly (about $80 \%$ of the time) by NNESTs (Brutt-Griffler, 2002; Canagarajah, 2005b; Seidlhofer, 2001). A study with academic and vocational ESL students found that most of the participants surveyed would prefer to be taught by NESTs, even though most of them were not able to accurately tell NESTs' from NNESTs' accents (Kelch \& Santana-Williamson, 2002). This marked preference for NESTs aside, ELLs have different perceptions of who makes a good teacher, and most have expressed generally positive attitudes toward NNES instructors when it comes to their general ability to teach the language. For example, even though students showed preference for NESTs when it came to pronunciation instruction, Hertel \& Sunderman (2009) found that students do not usually consider NNESTs to be inferior in all other categories.

What this all ultimately means for pronunciation instruction is that many ELLs who are not exposed to non-native pronunciations will likely equate proficiency with 
sounding native or native-like regardless of teaching context, and despite the literature showing native-like acquisition is not possible in most cases (e.g. Levis, 2005) and that "total elimination of an accent is not a realistic goal" (Breitkreutz et al., 2001). The disconnect that exists between aiming toward native-like pronunciation acquisition and the lack of information on the part of teachers and students alike regarding student selfperception, identity as it relates to accent, the context within which NNESTs and NNESSs will speak the language, and the fact that students are not sufficiently exposed to intelligibility approaches has prompted scholars to call for curricula development that includes WE accents and intercultural communication skills (Brown, 1995; Farrell \& Martin, 2009; Matsuda, 2003; Sifakis, 2004). Similarly, there have also been calls for the inclusion of multicultural perspectives that respect the $\mathrm{L} 1$ and $\mathrm{C} 1$ and teaches the $\mathrm{L} 2$ from a variety of perspectives where English is spoken (LoCastro, 2001; Kang, 2015), an approach that is largely absent from today's ELL classrooms.

The preceding sections have shown the research that exists regarding teacher attitudes and perceptions regarding their teaching practice in general and their approaches to pronunciation instruction, in particular. Student perceptions surrounding the factors that affect their L2 pronunciation acquisition, as well as their attitudes with regard to their own and their NNESTs' accents have also been explored. The next and final section in the review of the literature will explore the evolution of English pronunciation teaching over the years and current pronunciation materials and approaches, including the LFC in the context of ELF.

\section{EL Pronunciation Teaching Through the Years}

"Pronunciation seems to be the orphan of second language research and 
teaching"

(Derwing, 2010, p. 24)

At the turn of the last century, the International Phonetics Association introduced one of the most consequential tools for the categorization of L2 accent: The International Phonetic Alphabet (IPA). Through the use of the IPA, "pronunciation of a second language could be scientifically explained and improved" (Derwing \& Munro, 2009, p. 25), and scholars believed it would help ELTs achieve their goal of eliminating or reducing L2 accents. While the IPA helped produce significant work in the area of pronunciation teaching (e.g. Anderson, 1969), it did not achieve the classroom status its creators envisioned because it required extensive teacher training in phonetics and phonology. Despite this, pronunciation instruction was as important a component in ELT as grammar throughout the 1940s, 1950s and part of the 1960s. The last time pronunciation was still an important element in the ELT curriculum was during the audiolingual era-the ELT approach most widely employed in the United States and Britain around the 60s, 70s and part of the 1980s (Morley, 1991)-, but it also thrived under the Silent Way and the Oral Approach eras (Derwing, 2010).

By the 1970s and 1980s, questions had been raised about the effectiveness of pronunciation instruction and even if adult learners could manipulate their accents at all (Lenneberg, 1967). Around the same time, the communicative CLT began to establish itself as the preferred method for the teaching of English in all three circles of WE, relegating the audiolingual method to a secondary role. Curricula was affected by these methodological changes, and as a result pronunciation instruction was slowly dropped from the list of priorities in the EL classroom. New materials in areas like grammar 
increased all the while fewer pronunciation materials were produced during the same decades (Morley, 1991). Pronunciation materials that were produced mainly focused on whether to teach segmentals or suprasegmentals, with the latter being the most favored over the last three decades or so (Derwing, Diepenbroek, \& Foote, 2012; Derwing, 2003; Wei, 2006). By the 1990s and 2000s, some considered there was an "intercultural turn" (Borghetti, 2013), a post-method period of sorts (Kumaravadivelu, 1994) which opened up the possibility not only for taking up pronunciation instruction again, but for it to transcend the traditional supremacy of the NS models in favor of intelligibility and comprehensibility (Derwing, 2010). Levis (2005) believed that TESOL's "pronunciation

theory, research, and practice [were] in transition [and that] widely accepted assumptions such as the primacy of suprasegmentals, the superiority of inner-circle models, and the need for native instructors [had] been rightly challenged" (p. 376). At present, most researchers and scholars agree that accent is no longer the linguistic deficit it was perceived to be in years and decades past, as it has been shown that accent can be beneficial to ELLs self-identity, among other benefits (Derwing \& Munro, 2009). Despite this latest attempt at a resurgence of pronunciation instruction, most of the research mentioned above has not made its way into the curricula. Whenever pronunciation is taught, if at all, standard English varieties are still overwhelmingly favorited in EL classrooms.

\section{Pronunciation Materials and WE Focus}

According to Derwing and Munro (2009), it is the responsibility of the TESOL community to ensure that pronunciation research is applied to developing materials to be used in ELL classroom curricula. Currently, teaching materials for pronunciation are 
"one size fits all," seldom grounded in research (Levis, 1999), and developed from a speech pathology perspective with a focus on segmentals that doesn't take into account L1 differences among students (Derwing, 2003). An analysis of 12 general skill ELLs textbooks found, for instance, that they provided insufficient support for pronunciation teaching and learning (Derwing et al., 2012). Further, what materials exist focus on native pronunciation and leave out non-native (OC and EC) speakers, which leads students to assume native models are the only correct ones (Matsuda and Friedrich, 2012). Lack of OC, EC and non-standard IC accent representation in pronunciation materials has prompted scholars such as Jung (2010) to call for more student exposure to authentic materials that reflect the current reality of WE, not just the NES/SE perspective. The CLT approach, which has taken the focus away from pronunciation instruction, has also led to insufficient implementation of the existing WE research and relegated the WE perspective to non-essential coursework in TESOL training programs.

Textbooks are not the only materials teachers can use to expose their students to WE perspectives, however. Teachers can inform their practice by researching WE topics in academic journals; it is the job of ESL and EFL program administrators to make sure teachers have access journals and other sources, such as: English World-Wide (since 1979); World Englishes (since 1981); Indian Review of World Literature in English (since 2005); English Today (since 1984); and Arab World English Journal (since 2010). Journals on specific topics that include: World Literature Written in English Newsletter (since 1971); InMedia: The French Journal of Media and Media Representation in the English-Speaking World (since 2012); and, English for Specific Purposes World (since 2002). 
Teachers may also utilize voice corpora such as the Vienna-Oxford International Corpus of English (VOICE) and the International Corpus of English (ICE), where teachers can find spoken English samples from all 3 circles of WE. TV and internet resources are also available. Some examples include www.ndtv.com, a website that features Indian English videos and news; or the Channel News Asia online at http://www.channelnewsasia.com/news/ for news on Asia Pacific countries and Singapore.

Other widely known resources to WE scholars and teachers in TESOL programs are movies and documentaries that feature non-native/non-SE speakers of English in a variety of settings. These include: Mississippi Masala, El Norte, Dim Sum: A Little Bit of Heart, Break of Dawn, Living on Tokyo Time, The Story of English documentary series, Blue Collar \& Buddha, American Tongues, and others that not only provide students with exposure to various WE accents, but also promote critical discussion about issues central to the expansion of English around the world such as immigration, citizenship, power dynamics in relation to language, and those that provide unique opportunities for students to analyze their own viewpoint regarding these issues (D'Angelo, 2012). Finally, teachers may also become acquainted with ELF and LFC to add to their repertoire of non-standard English pronunciation teaching approaches.

\section{English as a Lingua Franca (ELF) and the Lingua Franca Core (LFC)}

Although contact languages such as English as a Lingua Franca (ELF) have existed for hundreds of years since the settlements of the first English colonies (Jenkins, 2011), ELF is a relatively new topic of research. It is sometimes used interchangeably with English as in International Language (EIL), as it is a type of English used during 
interactions NNESs conduct with other NNESs (Pickering, 2006) that came about on the heels of Kachru's (1985) World Englishes and as a response to pronunciation teaching standards based on written English models (Dauer, 2012). Despite the fact that ELF is the most widely used language variety in the world today, when it comes to the field of TEFL (Teaching English as a Foreign Language; the context where the majority of ELLs learn English nowadays) "what constitutes a target is still determined with virtually exclusive reference to native-speaker norms" (Seidlhofer, 2001, p. 135). Seidlhofer argues that in order for ELF to become a "feasible, acceptable and respected alternative to ENL (English as a native language) in appropriate contexts of use" (p. 150) it has to be codified in much the same way Standard English has been. Once codification has been achieved, Seidlhofer continues, this new resource could be utilized in ELT classrooms where cultural, social, educational and other factors would allow it.

The Lingua Franca Core (LFC) consists of an inventory of sounds Jenkins believed were necessary for successful ELF/EIL communication. These sounds include all consonants in the RP or SAE (Standard American English) inventory, except interdental fricatives $/ \theta /$ and $/ \delta /$; aspiration of initial voiceless tops $/ \mathrm{p} /, \mathrm{t} /$, and $/ \mathrm{k} /$; contrast between long and short vowels; and context-appropriate prosody, among others (Jenkins, 2002). The LFC offers an alternative to NS models to pronunciation instruction, but it requires at least a basic understanding of English phonology and phonetics, which, as discussed in the previous section, is not always available to TESOL students during training. On the other hand, using materials such as those listed in the previous section can easily expose students to a variety of dialects that can help them recognize and become familiar with the phonological differences between them, all 
without having to learn the IPA or becoming discouraged by yet another component of their learning process that may or may not produce the intended results. To this end, D’Angelo (2012) suggested that a more sensible approach to pronunciation instruction might be to focus on the aspects of accent that impede intelligibility on a student-bystudent and case-by-case basis, rather than "fixing" phonology to conform to RP or SAE.

\section{Conclusion to this Section}

The spread of English has resulted in a multiplicity of semiotic systems, several non-shared linguistic conventions, and numerous underlying cultural traditions.

(Kachru, 1985, p. 207)

Understanding the multicultural nature of today's English pronunciations provides teachers with a better foundation from which to confront the needs of students learning English in all three circles of Kachru's model. With regard to this point, Aya Matsuda (2003) argued that:

The limited exposure to English varieties in the classroom may lead to confusion or even resistance when students are confronted with different types of English users outside of class [...]. Even if one variety is selected as a dominant target model, an awareness of different varieties would help students develop a more comprehensive view of the English language. (p. 721)

That is, an IC instructor teaching International Students (IS) looking to return to their home countries may need to use SAE or RP examples sparingly and as part of the wider range of accents her students are likely to encounter. On the other hand, an EC teacher whose students' goals range from immigrating to an IC country, to students 
looking to gain basic skills in order to communicate with other EIL speakers may need to conduct periodic needs assessments to ensure, as much as possible, the needs of all her students are met (Matsuda, A. \& Friedrich, 2012). In other words, do NNESs need to be understood by other NNESs, by NESs (Murphy, 2013, p. 259), or both? A multicultural, multidialectal view of language instruction is not only supported in the ELL literature, but it can also be found across the literature for instruction of other languages. Fox (2002) declared that students need to learn as many types of French pronunciations as possible, as they are likely to encounter non-standard varieties in their daily interactions throughout their learning and upon leaving the classroom. And Hackl (1991) stressed exposing students of German to standard as well as non-standard varieties to aid in mutual intelligibility and comprehension. If a several-dialect approach is already favored for the instruction of languages with fewer speakers and far fewer dialects than English, as in the examples of French and German above, it seems unjustified to deny ELLs of the same opportunities learners of other languages already enjoy.

In each of the learning contexts described above and many others impossible to anticipate, reflexive instruction that is facilitated by student-centeredness and the minimization of perceptual mismatches will undoubtedly lead to better learning outcomes. Implementing teaching practices that embrace all English varieties as legitimate learning opportunities will continue to be a difficult task, however, despite encouraging examples of teachers across all Three Circles already using WE materials (including, as will be seen later, teachers in the present study). A more reflexive classroom begins with teachers achieving a thorough understanding of self and of student-teacher and student-student dynamics in relation to the students' personal 
backgrounds, their $\mathrm{C} 1 / \mathrm{L} 1$, and their English language development.

\section{Research Questions}

Having explored background topics that influence WE pronunciation instruction, the following sections will focus on describing and analyzing the results of the present study regarding the student and teacher participants' perceptions of WE accent. The research questions guiding this study were:

1. Are there any perceptual mismatches between the English varieties students want to learn and the varieties teachers want to teach, and do these perceptions differ depending on the learning context.

2. Does exposure to WE pronunciations change the students' and the teachers' perceptions of WE pronunciation varieties? 


\section{Chapter 3}

\section{Methods}

\section{Participants}

The present descriptive, quasi-experimental study was based on data gathered from ESL teachers and students over a period of one month via online surveys (Appendices 1,2). The study was designed for a minimum of 10 teachers and 20 students at each of two sites in the United States where ESL courses are taught: one school in the Midwest (MW) and a school in the Northwest (NW). Students in the MW location are mostly immigrants and refugees from Africa and Central and South America who receive free ESL classes, at times as part of their Adult Basic Education (ABE) instruction. The student population in the NW school is made mostly of student-visa holders from the Middle East and Asia and a minority of students from South America. All teacher participants were expected to be teaching at least one ESL course at the time they took the survey; all student participants were expected to be enrolled in level 4 or above ESL lessons (higher intermediate) in their respective schools.

\section{Pilot}

A pilot with two NNES participants of similar English competency to the students in this study was conducted to inform the researcher of any necessary changes to the student survey. At the time of the pilot, one participant was taking an EFL class and the other had graduated from an EFL program several years prior. These participants did not belong to either of the two schools and were not associated in any way with either the students or the teachers who took the survey whose answers were used for this study. The participants' feedback helped clarify the wording in some of the questions for the 
final version of the student survey. No pilots were conducted to clarify questions in the teacher survey.

\section{Instruments and Materials}

All participants answered the surveys via online Qualtrics Survey Software. Both groups of teachers received an "Invitation to Participate" (Appendix 3) via mass email with a link to their respective surveys. Students who took the survey learned about it from their teachers, from flyers at either of two locations on campus (NW students), or from a classroom presentation prompted by one of the teachers at the NW location. Each block of participants answered their own survey; e.g., the NW teachers' survey was separate from the MW teachers' survey, although both groups answered the exact same questions. Separating surveys this way allowed 1) Informed Consent (Appendices 4, 5) to be tailored to the participants' specific geographic location; and, 2) to have an accurate tally of participants for each of the four groups. All participants provided consent prior to answering any of the questions contained within the surveys. Participants who did not agree they met the required demographic and/or other minimum requirements were immediately thanked for their time, and the survey terminated at that time.

In addition to answering questions, teachers and students watched a 4-minute video half way through the survey. The video, entitled World Englishes on TED (https://www.youtube.com/watch?v=LBYsuohdKs4), is a compilation of TedTalk lectures given by English speakers from all 3 Circles of WE and posted on Youtube. The same 4minute video was used in the teachers' and the students' survey because it introduces (or further clarifies) WE in a straightforward manner that helped to improve the participants' comprehension of the topic. The video was used as the stimulus for the after questions 
and served to measure teacher and student changes in their perception of WE (if any)

after brief exposure to this material. Table 1 shows teacher pre-video to post-video answer correspondence and the research question/s it answers.

Table 1

Teacher Pre- and Post-video Paired Questions

\begin{tabular}{|l|l|l|}
\hline $\begin{array}{l}\text { Answers Research } \\
\text { Question: }\end{array}$ & Teacher Pre-Video Question & Teacher Post-Video Question \\
\hline 1,2 & 4-Importance of WE (personally) & $\begin{array}{l}\text { 3-Importance to get WE training } \\
\text { (personally) }\end{array}$ \\
\hline 1,2 & 5-Importance of teaching WE topics. & 2-Importance students learn about WE. \\
\hline 2 & $\begin{array}{l}\text { 7-ELLs can be successful even if } \\
\text { they can't understand WE. }\end{array}$ & $\begin{array}{l}\text { 4-Importance students be familiar with } \\
\text { WE accents. }\end{array}$ \\
\hline 2 & $\begin{array}{l}\text { 8-Regardless of WE training: } \\
\text { Importance of teaching WE. }\end{array}$ & $\begin{array}{l}\text { 6-How important is it to include WE in } \\
\text { curricula? }\end{array}$ \\
\hline $\begin{array}{l}\text { 2, Qualitative } \\
\text { Analysis }\end{array}$ & $\begin{array}{l}\text { 9-ESL speakers can be successful } \\
\text { even if they have an accent? }\end{array}$ & $\begin{array}{l}\text { 7-Students can be successful even if they } \\
\text { have an accent? }\end{array}$ \\
\hline Qualitative Analysis & $\begin{array}{l}\text { 10-What is “good pronunciation"? } \\
\text { 5-Do speakers in the video have "good } \\
\text { pronunciation"? }\end{array}$ \\
\hline
\end{tabular}

The teacher surveys consisted of a combination of Yes/No and Likert scale questions, in addition to demographic questions on age, first language spoken, highest education level, and others. There were a total of 10 demographic questions, 10 prevideo, and 7 post-video questions in the teacher survey. On the student side, the surveys consisted of 13 questions on demographics and 18 Yes/No and Likert scale pre-, and postvideo questions. Teacher and student answers were collected and later codified for analysis using numbers 1 through 4, where 1 represented the lower end in a 4-point scale and 4 the highest: 1=Strongly disagree, Completely Untrue, No; 2=Somewhat Disagree, Somewhat Untrue, Yes; 3=Somewhat Agree, Somewhat True; 4=Strongly Agree, Completely True. Because the answers were Likert-type, i.e., are ratio-category answers that cannot be assumed to be equally distributed, they were analyzed non-parametric 
tests. These results are shown in the quantitative section of this analysis. Table 2 shows student pre- to post-video answer correspondence and the research question each pair answers.

Table 2

Student Pre- and Post-video Paired Questions

\begin{tabular}{|l|l|l|}
\hline $\begin{array}{l}\text { Answers Research } \\
\text { Question: }\end{array}$ & Student Pre-Video Question & Student Post-Video Question \\
\hline 1,2 & $\begin{array}{l}\text { Q8-How important is it for teachers to } \\
\text { know WE topics? }\end{array}$ & $\begin{array}{l}\text { Q10-Importance teachers receive } \\
\text { training about WE topics. }\end{array}$ \\
\hline 1,2 & $\begin{array}{l}\text { Q5-Would like to learn more about } \\
\text { WE pronunciations. }\end{array}$ & $\begin{array}{l}\text { Q5-Would you take a “Accents of the } \\
\text { World" class. }\end{array}$ \\
\hline 2 & $\begin{array}{l}\text { Q7-ESL speakers can be successful } \\
\text { even if they can't understand WE. }\end{array}$ & $\begin{array}{l}\text { Q9-ESL speakers can be successful } \\
\text { even if can't fully understand WE. } \\
\text { Q6-Would you like teachers to use WE } \\
\text { materials? } \\
\text { Q8-Would you like your teachers to } \\
\text { Qse WE materials? }\end{array}$ \\
\hline 2 & $\begin{array}{l}\text { Q3-Can students be successful if they } \\
\text { have an accent? }\end{array}$ & $\begin{array}{l}\text { Q7-Can ESL speakers be successful } \\
\text { even if they have an accent? }\end{array}$ \\
\hline Qualitative Analysis & Q4-What is good pronunciation? & Q6-What is good pronunciation? \\
\hline Qualitative Analysis &
\end{tabular}

All 4 survey sections (two for each site) were open for about one month; 14 teachers and 6 students submitted completed surveys during this time. A total of 7 other participants either abandoned or chose not to finish surveys they had started. Those results were not part of the quantitative analysis, as those respondents either did not watch the video or did not provide enough post-video responses to answer the research questions. For most Likert-scale and Yes/No-type questions, teachers and students were also given the chance to expand upon their answers as much as possible. These answers are analyzed in the qualitative section in the next chapter. 


\section{Chapter 4}

\section{Data Analysis and Discussion}

Teacher survey responses were analyzed using a combination of quantitative and qualitative methods. In the case of the students' responses, the small sample size and the uneven split for each site (5 participants in the NW and 1 in the MW) did not allow for tests that measure differences or similarities between or within groups to take place. For this reason and because students' prose statements cannot be quantified, their responses were analyzed using qualitative methods only.

\section{Descriptive Statistics}

\section{Teachers.}

$79 \%$ (11) of teacher participants were 44 years of age or older and $21 \%$ (3) were between 31 and 43 years of age. All teachers in the NW school and all but 1 teacher in the MW school (Polish) were NES. The NW teachers all held MA TESOL degrees; one of the teachers in the MW school had no TESOL training, 2 had TESOL Certificates, and 4 had MA TESOL degrees. When it came to WE training, most teachers in the NW (8) indicated they had had some form of WE exposure: auditing a WE class (1), learning about WE as part of other coursework during TESOL training (3), or taking a WE class (4). Only one NW teacher had not learned about WE prior to taking the survey. As for the MW teachers, the numbers were more evenly split between having gotten at least some kind of WE exposure (5) and no exposure at all (4). A MW teacher had learned about WE in graduate school (1) while others considered exposure to various topics such as "dialects, history, phonetics;" "phonemics, phonetics;" "focus on British pronunciation" (3); and "lessons that created awareness (of WE)" (1) WE exposure. A 
teacher's assertion that a class or lecture qualified as WE exposure qualified it as such. No other subjective measures of what qualified as WE exposure and what didn't were used.

\section{Students.}

Half of the student participants were between the ages of 18-21, 2 between $30-34$, and one between 25 and 29 years old. Half the students (all in the NW location) were native Arabic speakers and the remainder three were one each Portuguese, Persian, and French native speakers. All but one of the students had been in the US less than 1 year and the remaining one between 1 and 3 years. Students' length of English learning ranged from 0-5 months (4), 6 months to 1 year (1) and 1-2 years (1).

Only completed surveys where teacher and student participants answered both the pre- and the post-video portions were used for the quantitative and qualitative analyses. Partial responses were not used for either the quantitative or qualitative analyses of the data.

\section{Quantitative Analysis}

RQ\#1-Are there any perceptual mismatches between the English varieties students want to learn and the varieties teachers want to teach, and do these perceptions differ depending on the learning context (Midwest school vs. West Coast school)?

Regarding teacher and student perceptions on WE instruction, the means for answers to paired questions (where the first number in the pair shows the pre- and the second the post-video answers; tables 3 and 4) 4 and 3, and 5 and 2 on the teacher side; and questions 8 and 10, and 5 and 5 on the student side were used. Teacher questions 4 
and 3 asked how important teachers believed WE training is to their teaching practice and questions 5 and 2 asked how important they thought it was that their students learn about WE. The means for the first set of questions on the teacher side were $\mathrm{M}=2.64$ and $\mathrm{M}=2.57$, respectively; the means for questions 5 and 2 were $\mathrm{M}=2.86$ and $\mathrm{M}=2.71$, respectively (Table 3). All four questions were on a 1-4 scale with 1 representing the least and 4 the most agreement. For both sets of answers, most teachers answered it was at least "Somewhat Important" that WE be part of their and their students' ESL learning experience; however, the results also show that teachers were slightly more in favor of their students learning about WE than they were about receiving WE training themselves. Similarly, teachers' answers showed they were slightly less in favor of WE training and WE teaching (respectively) after watching the video than before watching the video.

Table 3

Teacher Perceptions regarding WE Instruction

\begin{tabular}{|l|l|l|l|l|l|c|}
\hline $\begin{array}{l}\text { Pre-Video Survey } \\
\text { Question (Q) }\end{array}$ & $\begin{array}{l}\text { Post-Video Survey } \\
\text { Question (Q) }\end{array}$ & $\mathrm{N}$ & Min & Max & Mean & Range \\
\hline $\begin{array}{l}\text { Q4-Importance } \\
\text { of WE training }\end{array}$ & $\begin{array}{l}\text { Q3-Importance WE } \\
\text { training }\end{array}$ & 14 & 2.00 & 3.00 & 2.57 & $1-4$ \\
\hline $\begin{array}{l}\text { Q5-Importance } \\
\text { of Teaching WE }\end{array}$ & $\begin{array}{l}\text { Q2-Importance } \\
\text { Students Learn WE }\end{array}$ & 14 & 1.00 & 4.00 & 2.64 & $1-4$ \\
\hline
\end{tabular}

Students' answers to question 8 , or how important they thought it was for their teachers to know WE topics and question 10, on their attitudes regarding their teachers receiving WE training; and question 5, or whether or not they would like to learn more 
about WE pronunciation and question 5, regarding how important they believe WE is to their own learning objectives resulted in a $\mathrm{M}=3.0$ ( $\min$. value $=2$, max value $=4$ ) and $\mathrm{M}=1.8$ (min. value=1, max. value=2) for the first set of questions; and $\mathrm{M}=1.5$ and $\mathrm{M}=1.8$ ( $\min$. value=1, max. value $=2$ ) for the second pair (Table 4). Student scores for how important their perceived WE training was for their teachers, as well as how important they believed WE was for their own learning process improved after watching the video in relation to their initial opinion, even though, in both cases, their perceptions were mostly positive. Also, when comparing the teachers' to the students' responses, the students viewed WE slightly more positively both when it concerned their own learning and their teachers' professional development than did the teachers. A further explanation of teachers' and students' perceptions regarding WE instruction is provided in the qualitative section of this analysis.

Table 4

Student Perceptions of WE Teaching

\begin{tabular}{|l|l|c|c|c|c|c|}
\begin{tabular}{|l|l|l|l|} 
Pre-Video Survey \\
Question (Q)
\end{tabular} & $\begin{array}{l}\text { Post-Video Survey } \\
\text { Question (Q) }\end{array}$ & $\mathrm{N}$ & Min & Max & Mean & Range \\
\hline $\begin{array}{l}\text { Q8-Importance that } \\
\text { teachers are familiar } \\
\text { with WE }\end{array}$ & 6 & 2.00 & 4.00 & 3 & $1-4$ \\
\hline & $\begin{array}{l}\text { Q10-Importance } \\
\text { that teachers get } \\
\text { WE training }\end{array}$ & 6 & 1.00 & 2.00 & 1.83 & $1-2$ \\
\hline $\begin{array}{l}\text { Q5-Would like to } \\
\text { learn about WE } \\
\text { pronunciations }\end{array}$ & $\begin{array}{l}\text { Q5-Importance of } \\
\text { learning about WE }\end{array}$ & 6 & 1.00 & 2.00 & 1.83 & $1-2$ \\
\hline
\end{tabular}

In answer to the question of whether or not teacher perceptions differed depending 
on the NW or MW locations, a General Linear Model Repeated Measures found there was no main effect for questions 4 and 3 within each site $(F=0.176 ; p=0.68)$, or when comparing teachers' answers between locations $(\mathrm{F}=0.05 ; \mathrm{p}=0.822)$. Similar results were found for questions 5 and 2. The null hypothesis that location did not influence the teachers' answers could not be disproven. A similar test was not performed on Student data due to the small sample size and uneven student distribution.

RQ\#2 Does exposure to WE pronunciations via a four-minute video clip change the students' and/or the teachers' perceptions of WE pronunciation varieties?

On the teachers' side, a Wilcoxon test for Related Samples on paired questions 4 and 3,5 and 2, 7 and 4,8 and 6, and 9 and 7 was run to determine if teachers' perceptions on WE changed after brief exposure to WE topics and whether changes, if any, were statistically significant. The tests found no statistically-significant differences between pre- and post-video answers for any of the pairs tested. Responses to pre-video questions 4 and 5, as compared to post video questions 3 and 2, either shifted to a slightly more negative perception (pair 4 and 3), or remained the same (pair 3 and 2). In either case, these changes could not be attributed to the teachers' exposure to WE from watching the video. Teachers' answers to these two sets of questions scored lower both for the importance of WE in teachers' professional development, as well as for the importance of teaching WE and/or for their students learning about this topic than did students' answers (student answers will be analyzed using qualitative methods later). Similarly, Related-Samples test results on question pairs 7 and 4 (Sig.=.132), 8 and 6 (Sig.=.589), and 9 and $7($ Sig.=.180) did not disprove the null hypothesis that the videos would not influence the teachers' perceptions of WE, either positively or negatively. 
Students' results in relation to the WE stimuli will be explained in the qualitative section of this analysis.

\section{Qualitative Analysis}

Due to the small samples that resulted from low teacher and student participation at both sites, a qualitative analysis of the written answers complements the quantitative analysis that, as shown in the previous pages, produced no statistically-significant results. The following interpretive analysis will help the reader better understand the complexities of the teacher as well as the student attitudes through the analysis of the participants' own words provided during their elaboration on Yes/No and Likert-type answers.

\section{Perceptions about accented English.}

Pre- and post-video Yes/No Questions 3 and 7 asked students whether they believed it was possible for accented speakers of English to be successful in the Englishspeaking world, and all but one responded affirmatively both before and after watching the video and the remaining student changed his/her answer from "yes" to "no" after watching the video. One student believed that it was possible for English speakers with accents to be successful "because the accent is just a detail, what really matter is the content [sic]," while another also responded affirmatively but with a caveat: "Possible, but depends on other more skills [sic]" and a third student was even firmer on his/her answer: "as long as you're able to make yourself understood, it is fine." In most cases, the student participants indicated that they were comfortable with accents, yet when asked (pre-video) whether they themselves were accented speakers of English, only half answered firmly "Yes", one firmly "No", and two others that they spoke with accents 
only "Sometimes." Based on the average time the students have lived and/or studied ESL in the US (in both cases a minimum of 0-5 months and a maximum of 3 years); the fact that most students fell well outside the Critical Period window (three students were between the ages of $18-21$, one between $26-29$, and two between 30 and 34 years of age; and that most respondents (5) only speak English with teachers and other English students, it is unlikely that they have either completely lost their accents or that they have the ability to switch between accented and SAE at will. Further, these students' positive perceptions of accent did not appear to imply self-inclusion in the group of accented English speakers as four of the six perceived "good accent" as "speaking well enough so that others can understand me" and from the remainder two one rated "good accent" as the ability to speak "well enough so that others wouldn't know English wasn't [his/her] first language" and the other as "sounding like a native speaker." When asked specifically about their own accents, (which 5 students said they had), 4 students indicated that they would like to speak like native English speakers, and only one that they liked their accent. Only after watching the video did several students switch from mostly disliking their accent to either liking it (3) or being somewhat indifferent to it (2).

\section{WE classroom implementation.}

A qualitative analysis of teacher answers to the question of whether or not they had received WE training prior to taking the survey reveals that most of these teachers did not know what WE means. As shown in the descriptive statistics section in this study, many teachers linked WE pronunciations with knowledge of Phonetics and Phonology (e.g. "In Poland; part of my studies at university - it deal with phonetics, phonemics, etc.;" "Linguistics studies at [US university], incl. dialects, history, phonetics;" etc). 
Only one teacher in the MW school expressed he/she understood WE as the legitimization of non-standard varieties: "When I was in my MA TESOL program, I recall lectures or lecture content about the fight to "legitimize" (so to speak) *native-like* proficiency; for example, pushing for schools to accept the legitimacy of both native and native-like speakers as their English instructors." Even though the legitimization of "native-like proficiency" hardly encompasses the legitimization of ALL varieties of WE, this characterization was the closest approximation to an actual definition of WE among all teacher respondents which may, in a way, explain their relatively low scores regarding teachers' WE implementation in the classroom, their view of its importance in the ELT curricula, and other similarly negative perceptions around WE.

When asked how important it was for their students to be exposed to WE pronunciations, a majority of teacher respondents answered it was only slightly important. One teacher in particular believed how much WE exposure students get "depends on what other Englishes they will be exposed to in their future lives. Some may experience many while others may experience only a few with regularity." Another teacher had a similar perception about the places and times their students will/should encounter NNES pronunciations:

A lot of comprehension comes with adapting to other pronunciations. The more they hear it, the more they will understand it (...). I had a difficult time understanding some of my (heavy-accented students), but over time, I understand the accent better because I hear it a lot.

Both answers assume students will and perhaps should only learn about WE pronunciations outside the classroom, which might also explain why a majority of the 
teachers surveyed don't consider WE an important aspect of ELL. Another teacher pointed out that "Exposure to other accents is good, but not a priority," and yet another that "Students are likely to succeed at some level regardless of instruction." One respondent who believed it was Completely Unimportant students learn WE expressed the concept "might be interesting, but I don't think it does much to help them learn." However, when teachers were asked whether they had ever incorporated WE perspectives into the curricula, 7 out of 9 and 5 out of 9 teachers in the NW and MW, respectively, reported using WE materials and/or pointing out to their students some differences among English dialects only sometimes.

By contrast to their teachers' attitudes, when asked if they thought it was important to learn what other English speakers around the world sound like 5 out of the 6 students (post-video) said they would take a class entitled Accents of the World or English Around the World. Students' opinions on the advantages of these two classes varied, but they were generally in favor of the idea: "Yes, it would be nice to learn how other accent sounds[sic]" and "Practices are helpful[sic]." Only one student of the six surveyed said they "would like to learn about speaking from native speaker[sic]." Even from a student sample as small as the present one, it can be observed from the students' responses that their support in favor of learning about other accents is more enthusiastic than their teachers might have believed and/or would encourage their students to explore.

\section{Self-perception of accent as a predictor of classroom WE implementation.}

An analysis of teacher responses on their self-perception of accent, TESOL, and WE training shows it is hard to predict whether teachers would implement WE based on demographics alone. More teachers in the NW indicated they speak with an accent (5) 
compared to only 3 in the MW (including the NNEST). Almost all the teachers at both locations had taught EFL outside the US (all 9 in the NW and 7 out of 9 in the MW) and also a majority ( 8 in the NW and 5 in the $\mathrm{MW}$ ) had received some kind of WE training ranging in amounts and types of exposure. Wide ranging backgrounds and selfperceptions of accent such as these could have prompted a similarly wide range of responses from teachers based on their cognition at the time, yet there was virtually no difference (as shown in the quantitative analysis) on how these two very different sets of teachers approached WE.

\section{Teacher perception of the importance of WE in their own practice.}

Teachers' perception that it is more important for their students than it is for themselves to receive WE training was also consistent with the literature on teacher perceptions of WE. The literature has shown that it is not enough for teachers to know about WE but that, for a paradigm shift from standard English to WE to take place, teachers need to spend considerable more quality time deepening and applying their knowledge of WE (Brown, 1993) than most of the teachers in this study believed was necessary. Even teachers who had studied WE for a whole term did not believe WE was a central aspect of their practice and did not incorporate it explicitly in their syllabi, or in a manner conducive to teacher-student and student-student critical inquiry about the impact of WE in the students' short and long-term learning goals. Some teachers cited time constraints, and others the personal belief that their students didn't need to know about WE. These sentiments, again, contrast with the students' favorable views of WE and it points to the presence of perceptual mismatches (Kumaravadivelu, 2003) of the communicative, pedagogic, and attitudinal kind that are preventing students from having 
access to information they would like to get.

As shown in this analysis of the teacher and student participants' responses, students had generally more positive attitudes regarding WE post- compared to pre- WE stimuli, as well as when it came to an intellectual curiosity to learn more about these English varieties, compared to their teachers. Teachers, by contrast, had the same or slightly less-positive attitudes toward WE after watching the video than they did prior to, as well as toward implementing WE in their classrooms. The implications of this mismatch between teacher and student perceptions of the importance of WE will be discussed in the following section.

The shift in students' perceptions after watching the video from mostly disliking to mostly liking their accents, in addition to their more positive outlook regarding the use of WE in the classroom, shows that students may be more susceptible to even small amounts of WE stimuli than initially thought, especially compared to their teachers. As mentioned in the review of the literature, it often takes intensive training and the extensive application of WE topics in the ELL classroom for teachers to perceive it as a valuable component in their curriculum. On the other hand, the results of the present study are encouraging for students and teachers in that even teachers who have time and/or resources constraints can promote students' critical assessment of WE in their ESL attainment through class materials and exercises which may, in turn, achieve healthier student self-identities with relation to their accents.

\section{Limitations}

One limitation of this study was the small number of teacher and student participants. This was due to lower MW teacher and student participation in ESL courses 
than in previous terms because of budget cuts during the term the survey was conducted. A smaller active-teacher pool also resulted in fewer students taking ESL courses at the time the survey was conducted, and even fewer who met the minimum required course level 4 or above. Because of this reason, a decision was made to open the invitation to participate to all teachers and students regardless of whether they were teaching or taking classes at the time; for this reason, it is not possible to ascertain all MW teacher participants had been teaching at the time they took the survey or that the student was taking a class at the time he or she took the survey, as it is with the NW participants.

The fact this study was conducted within an ESL context and with a majority NESTs also poses the question of whether results might have been much different in an EFL context in an OC or EC environment. It is not possible to determine if the results of this study might parallel a similar study in the contexts mentioned above.

\section{Discussion}

The purpose of this study was to identify teacher and student perceptions regarding WE pronunciations before and after the participants were exposed to WE stimuli, and the results show that teachers and students had generally positive attitudes toward WE. Even though the test results were not found to be statistically significant in the teachers' case (no statistical tests were run for the student responses), an important difference between teacher and student answers was that the students had slightly more positive perceptions after WE exposure than their teachers. The student results are in line with the literature, which has shown that students who were exposed to a wider range of accents had better perceptions of their own and other NNES accents than students who did not have the same exposure (e.g., Bayyurt \& Altinmakas, 2012; Madden \& Moore, 
1997; and Tokumoto \& Shibata, 2011). Student results are encouraging, as they show student self-perception of accent may be sensitive to positive WE stimuli. On the other hand, teachers did not believe WE was as important to student success and, even though some of them used WE materials in their lessons, they perceived their ability to implement this perspective as separate from their professional development and/or their knowledge of the topic. This perception may point to a belief among teachers that they have sufficient breadth and depth of knowledge of WE, when in fact the results of this study, similar to what was found in the literature, suggest teachers' knowledge of WE needs time and effort to evolve and develop.

Despite encouraging signs in recent years that TESOL has been moving toward learner-centeredness (Derwing and Munro, 2009), a teaching philosophy that allows for innovative approaches such as WE to enter the classroom, pronunciation instruction within the WE framework still poses a serious dilemma for TESOL professionals: Research tells us that many ELLs want to achieve native-like fluency, as did some of the students surveyed for this study, yet a vast majority of these students don't know NNES varieties are also legitimate, about the $\mathrm{CPH}$, or about the fact WE speakers like them (including NNESTs) represent the majority of English speakers in the world today. Without this information, ESL and EFL students are at a disadvantage compared to other disciplines (where exposure to most if not all different perspectives in a specific area of study is standard practice) and even to learners of other L2s, as seen in the literature. And while the $\mathrm{CPH}$ has not been conclusively proven, there hasn't been a position to challenge its claim that accent will likely be present if the onset of language acquisition is past adolescence or even earlier, either. Scholars such as Marinova-Todd et al. (2000), 
who believe that "most adult learners fail to engage in the task [of acquiring native-like English pronunciation] with sufficient motivation, commitment of time or energy, and support from the environment" (p. 27) also fail to acknowledge that only a minority of ELLs would be able to devote such a commitment of resources to the non-essential task (to their overall EL2 attainment) of sounding like a native English speaker. Sentiments such as these scholars' only fuel the belief among TESOL professionals that students who don't make supreme efforts to get rid of their accents will always be "deficient" (Jenkins, 2006; Kachru, 1996) compared to NES. But this viewpoint is not exclusive to NESs with regard to NNESs. The following excerpt illustrates how a NNEST perceived her accent in relation to native speaker accent, as reported in Sayer (2012, p. 171):

[T]he native speaker is always going to be more than us, you know?(...)this conception if you like or ideology that we have to be-or that we can't turn ourselves into, or talk $100 \%$ like they talk, $[\ldots]$ here in Mexico we can't achieve that. Sure we can talk and we can communicate, but we are lacking, you know?[...] you can manage to APPROXimate the sounds, but you'll never, if you like, get to 100 percent...perfection like they are, or like we believe or idealize the native speaker to be. (italics used for emphasis).

NE "perfection" of which this teacher speaks brings to mind images of Colonel Pickering trying to de-cockneyfy Eliza Doolittle in My Fair Lady. For decades or even centuries since the first EL classes were first taught, accents that depart from "the norm" have been thought to be less than ideal. Yet Cockney English has not disappeared, nor have NNES accents decreased in amount or variety in any of the three circles of WE. On the contrary, regional accents in IC as well as OC and EC countries have multiplied over 
the last fifty years, a phenomenon that can attributed to increased mobility, immigration, and a globalized economy. But, for some reason, accent-based discrimination also appears to have risen. From personal experience as a non-native speaker of English as well as from what can be found in the literature, it would seem that discrimination that appears to be based on accent often has less to do with "strange" phonology and more with skin color, national origin, perceived legal status, and other factors that may have nothing to do with speech (e.g. Kubota \& Ward, 2000; Lippi-Green, 2011). If this were not the case, European-accented English speakers wouldn't be thought of as more sophisticated (Derwing \& Munro, 2009) than other L1 English speakers. As one teacher in this study remarked:

I think $[\ldots]$ it is important $[\ldots]$ for students to know that there are a variety of English accents and that comprehensibility is more important. However, in the real world, this will not stop prejudice against English speakers who do not follow some "standard".

A more sensible approach to current teaching practices would be for NESTs to use as many WE materials as possible, and for NNESTs to aim toward their own intelligibility while making sure students understand differences as well as similarities between their accent and NES accents. Or, in other words, fighting prejudice with information about the options students have regarding their own pronunciation outcomes. Regardless of the reasons for the current diversity of Englishes and the accompanying prejudice against other-accented English speakers, ELT practices that are dictated by fear students will face this type of discrimination are no longer sustainable. WE acquisition will not hinder a student's ability to learn to communicate in English. On 
the contrary, it will aid in that process by developing her inter-cultural awareness and by giving her a more thorough understanding of how to accommodate and normalize for other English speakers' accents, how to self- and other-repair when communication breakdowns occur, and how to negotiate meaning through pragmatic strategies. Perhaps more importantly, she will learn that her variety of English, whether accented or not, in accord with her own judgement of whether it's best to aim for native-like or accented pronunciations, has the power to project her own individuality and, as such, she deserves the respect of native and non-native English speakers alike.

\section{Implications and Recommendations}

\section{For teachers.}

Teachers may find the results of this study useful to compare to their own and their students' views of WE and the place it occupies in their classroom. As the video did for the students in this study, small adjustments to existing curricula through the incorporation of materials (videos, movies, conversations, group work, etc.) that highlight speakers from all 3 circles of WE may be a first step toward improving students' perceptions of their own and others people's accents ${ }^{5}$. A multicultural, multidialectal approach to classroom practices may lead to increased comprehensibility of others' accents as well as better intelligibility of the students' own accents. As shown in this study, teachers are not currently using student feedback to determine the types and amounts of WE materials they need to use in their lessons. Teachers should encourage student discussion about who their interlocutors are or may be in the future while also

\footnotetext{
${ }^{5}$ For a comprehensive sample of lesson plans and other WE resources see Bayyurt and Altinmakas (2012), Hino (2012), and Matsuda and Duran (2012).
} 
emphasizing that exposure to a wide range of accents is, even in a worst case scenario, an opportunity for students to become familiar with how people around the world pronounce English. Special attention should also be paid to students who, after having a thorough understanding of $\mathrm{CPH}$ and $\mathrm{WE}$-most likely students enrolled in higher intermediate and advanced courses-feel native-like pronunciation fits their learning and/or personal goals best. Teachers should familiarize themselves with phonetics resources such as the University Of Iowa's phonetics website at http://soundsofspeech.uiowa.edu/english/english.html. They should also have phonology practice sheets with, among other things, minimal-pair practice exercises (e.g. Avery and Ehrlich's (2012) Teaching American English Pronunciation and Celce-Murcia, Brinto and Goodwin's (2010) Teaching Pronunciation) readily available for their students in case they express an interest in learning how to speak with a native accent. Teachers should also emphasize that it takes high levels of commitment to the task of learning the L2 phonology and high self-motivation and support from the environment (from family, friends and other teachers) to achieve this goal (Marinova-Todd et al., 2000). Student success will depend, in great measure, on their thorough understanding of the importance of the factors mentioned above, and copious amounts of work and dedication their teachers should prepare them for. Finally, teachers who implement procedures toward a paradigm shift from nativeness to WE/intelligibility approaches will experience strong, either positive or negative, student reactions to the topic of WE. Teachers need to prepare themselves to resolve questions and/or concerns arisen from their students deciding to follow either approach, as well as to provide them with the support and encouragement needed to pursue their chosen option. 


\section{For TESOL training programs and ESL/EFL program administrators.}

TESOL programs would be advised to include mandatory intercultural competence and WE training in all MA-TESOL programs. These courses should also be recommended for TESOL certificate students. At a minimum, TESOL programs should make these courses available to all MA TESOL and certificate students in Methods classes. In all cases, these classes should include student-teacher training on how to help their future ELLs deal with accent-based prejudice and discrimination through classwork and group activities; e.g., related to circumstances depicted in any of the movies listed in the materials section in the literature review. Both TESOL and ESL/EFL program administrators would also be advised to facilitate NNES resources for classroom use by their instructors. Faculty diversification will also help TESOL trainees as well as ELLs in all Three Circles benefit from these teachers' unique perspectives about the place of English in their lives. Finally, offering at least one WE class for advanced ELLs would solidify WE concepts students learned throughout their education.

As indicated by Canagarajah (2016), the individual domains of study within TESOL don't always develop in a parallel way. Where innovations in methodology or SLA approaches have made their way to the classroom fairly quickly and in keeping with research, others such as 35-year-old WE have not. It is imperative that ESL and EFL program administrators, aided by teacher input from planning to implementation, increment the amount and the quality of WE materials and approaches in ELL. By engaging with teachers in healthy discussion about the very different landscape of today's English compared to only 40 years ago, program administrators will encourage more reflexive and reflective practitioners who are better trained to deal with their students' 
expectations for learning outcomes.

\section{For future research.}

It would be useful for EL teachers and program administrators alike to conduct research in the area of WE classroom implementation, as well as whether implementation of a curriculum with an explicit WE component would help students improve their selfperceptions of accent. There also needs to be more research on ELLs perceptions of

fluent accented ESL speakers as role-models of pronunciation (e.g., Murphy, 2013). Examining how teacher cognition affects perceptions of WE and its implementation within the curricula is another area worth exploring. And as Canagarajah (2016) pointed out, there also needs to be more research into the history of English as a subject topic in Outer and Expanding circles practices. More research is also needed in the area of NNESTs' views of WE and its implementation in the classroom. Finally, a study on student identity regarding L2 (with/without regard to L1) accent would also be beneficial for teachers' understanding of student/accent dynamics.

\section{Chapter 5}




\section{Conclusions}

The purpose of this thesis was to find out how teachers and students felt about "accented" English and its use in the ELT classroom. In this regard, only a small portion of the results was at all surprising to me: the fact that the majority of the students surveyed, with so little as a brief 4-minute exposure to World Englishes, expressed they would welcome its addition to their ESL instruction. This is particularly surprising because this study also showed a majority of the teachers surveyed do not use WE in the classroom and those who do, do so implicitly without creating opportunities for their students to critically assess the role of WE in their ultimate language attainment. Those teachers who only address pronunciation sporadically or on a case-by-case basis overwhelmingly use IC English because it is implicitly accepted (by the TESOL community as a whole) to be the standard to which students should adhere. There is also a feeling among English instructors that, if interested in incorporating WE in their curricula, ESL program administrators might not support WE instruction because it is believed, again, implicitly, that students might not take well to that kind of content.

We, the TESOL community in charge of spreading English around the world, have sheltered our students from the imaginary harm WE might do to them. We are withholding useful and irreplaceable knowledge. We appear to have forgotten that our students can (and should) be supported in making their own choices regarding their learning. We are denying them of the right to be discerning learners and face the challenge to decide for themselves whether to go the native speaker route, or to develop the courage to conclude accented English should afford them as many opportunities to succeed in the real, English speaking world as non-accented English — there may come a 
day when choosing the most likely outcome, speaking accented English, might no longer be seen as a "courageous" move but simply the consequence of learning English at a later age-. In sum, we are robbing our students of learning opportunities that are unadulterated by our institutionalized bias against all non-native Englishes.

Why, then, did the students in this study see benefits to learning about WE when they have hardly been shown that these are important or worthy of any instruction time?

In order to answer this question, I find it useful to first acknowledge that ELT is one of only a few topics of instruction where important factors that influence learning outcomes such as explicit instruction, the development of critical thinking skills, and the exploration of contrasting or differing views on the same topic (nativeness vs. intelligibility are at or near the top of this list) are often left unsaid, unexplored, and untaught. We-the TESOL community-haven't learned how to be inclusive even when the very nature of teaching English means bringing people from seemingly distant cultural, ethnic, linguistic and other backgrounds closer together. We don't go there, perhaps, because we are paralyzed by the fear we will be partly responsible for our students facing overt discrimination if we allow them to be accented English speakers. Or, maybe, those at the top of the TESOL ladder do not want to be responsible for accented English being "a new normal," as though it were not, already. Or, dare I say, might there be more sinister reasons behind excluding a majority of English speakers' accents from ESL (and EFL) curricula and materials? Have we simply become accustomed to student participation instead of membership in the English-speaking community, or is this exclusion done on purpose? Conspiracy theories as these might sound, any of these explanations is as good as any one justification any TESOL administrator, scholar, 
program administrator, or ESL instructor might have offered to date for keeping our students in the dark about what we all have known for over 30 years: WE are here to stay.

If it seems like there are more questions than there are answers regarding the absence of WE in the ELT classroom, it is because there are no satisfactory answers to be given. I have no doubt that more instructors would embrace WE as an integral, can't-dowithout component in their lessons if they were offered the training and the encouragement to incorporate it into their lessons. But it is not only up to teachers to deliver this long overdue perspective to ELLs; teachers are merely the vessel through which the TESOL community as a whole, teachers included, can fulfill its responsibility to present ELLS with all choices available to them. So, perhaps the answer to the question why students were so open to learning about WE is a simple one: ELLs come into our classrooms ready to embrace learning. The more important question then becomes: When will TESOL start to meet the challenge?

\section{References}


Aboud, F. (2009). Modifying children's racial attitudes. In J. Banks (Ed.), The Routledge International Companion to Multicultural Education (pp. 199-209). Hoboken, NJ: Routledge.

Alvarez, L. \& Kolker, A. (Producers) \& Alvarez, L. \& Kolker, A. (Directors). (1988). American Tongues. United States: PBS.

Anderson, T. (1969). Linguistics and the teaching of pronunciation. ERIC Clearinghouse.

Baker, A. (2011). Discourse prosody and teachers' stated beliefs and practices. TESOL Journal, 2(3), 263-292.

Baccaglini, G. W. (2013). Emerging from English as a foreign language to English as an international language within a changing global context: Case studies. (Doctoral dissertation). Retrieved from ProQuest LLC. (UMI Number: 3602951).

Baxter, J. (1980). How should I speak English? American-ly, Japanese-ly, or internationally? JALT Journal, 2, 31-60.

Baxter-Magolda, M. B. (2000). Teaching to promote holistic learning and development. New Directions for Teaching and Learning, 82, 88-98.

Bayyurt, Y. \& Altinmakas, D. (2012). A WE-based English communication skills course at a Turkish university. In A. Matsuda (Ed.), Principles and Practices of Teaching English as an International Language (pp. 169-182). Bristol: Multilingual Matters.

Borg, S. (2003). Teacher cognition in language teaching: A review of research on what Language teachers think, know, believe, and do. Language Teaching, 36(2), 81109. 
Borghetti, C. (2013). Integrating intercultural and communicative objectives in the foreign language class: A proposal for the integration of two models. The Language Learning Journal, 41(3), 254-267.

Brannan, D., \& Bleinstein, T. (2012). Novice ESOL teachers' perceptions of social support networks. TESOL Quarterly, 46(3), 519-541.

Breitkreutz, J., Derwing, T., \& Rossiter, M. (2001). Pronunciation teaching practices in Canada. TESL Canada Journal, 19(1), 51-61.

Breshears, S. (2004). Professionalization and exclusion in ESL teaching. TESL Canada Journal, 4, 23-39.

Brown, K. (2002). Ideology and context: World Englishes and EFL teacher training. World Englishes, 21(3), 445-448.

Brown, K. (2001). World Englishes and the classroom: Research and practice agendas for the year 2000. In E. Thumboo (Ed.), The Three Circles of English. Language Specialists Talk about the English Language (pp. 371-382). Singapore: UniPress.

Brown, K. (1995). World Englishes. To teach or not to teach? World Englishes, 14(2), 233-245.

Brown, K. (1993). World Englishes in TESOL programs: An infusion model of curricular innovation. World Englishes, 12(1), 59-73.

Brutt-Griffler, J. (2002). World English: A study of its development. Clevedon, England: Multilingual Matters.

Canagarajah, S. (2016). TESOL as a professional community: A half-century of pedagogy, research, and theory. TESOL Quarterly, 50(1), 7-41.

Canagarajah, S. (2005a). Editor's Note. TESOL Quarterly, 39(3), 365-366. 
Canagarajah, S. (2005b). Reclaiming the local in language policy and practice (ESL and Applied Linguistics professional series). Mahwah, NJ: L. Erlbaum Associates.

Cleveland-Innes, M., \& Emes, C. (2005). Principles of Learner-centered curriculum: Responding to the call for change in Higher Education. The Canadian Journal of Higher Education, 35(4), 85-110.

Cran, W. (Director). (1986). The Story of English. United States: McNeil-Lehrer Productions.

Cray, E. (1997). Teachers' perceptions of a language policy: "Teaching LINC". TESL Canada Journal, 15(1), 22-38.

Crystal, D. (2008). Two thousand million? English Today, 24, 3-6.

D'Angelo, J. (2012). WE-Informed EIL curriculum at Chukyo: Towards a functional, educated, multilingual outcome. In A. Matsuda (Ed.), Principles and Practices of Teaching English as an International Language (pp. 121-139). Bristol: Multilingual Matters.

Dalton-Puffer, C., Kaltenboeck, G., \& Smit, U. (1997). Learner attitudes and L2 pronunciation in Austria. World Englishes, 16(1), 115-128.

Davydova, J. (2012). English in outer and expanding circles: A comparative study. World Englishes, 31(3), 266-385.

Derwing, T., Diepenbroek, L., \& Foote, J. (2012). How well do general-skills ESL textbooks address pronunciation? TESL Canada Journal, 30(1), 22-44.

Derwing, T. (2010). Utopian goals for pronunciation teaching. In J. Levis \& K. LeVelle (Eds.), Proceedings of the 1st Pronunciation in Second Language Learning and 
Teaching Conference (pp. 24-37). Ames, Iowa: Iowa State University.

Derwing, T., \& Munro, M. (2009). Putting accent in its place: Rethinking obstacles to communication. Language Teaching, 42, 476-490.

Derwing, T., Munro, M., \& Thomson, R. (2007). A longitudinal study of ESL learners' fluency and comprehensibility development. Applied Linguistics, 29(3), 359-380.

Derwing, T., \& Munro, J. (2005). Second language accent and pronunciation teaching: A research-based approach. TESOL Quarterly, 39(3), 379-397.

Derwing, T. (2003). What do ESL students say about their accents? The Canadian Modern Language Review, 59(4), 547-566.

Derwing, T., \& Rossiter, M. (2002). ESL Learners' perceptions of their pronunciation needs and strategies. System, 30, 155-166.

Derwing, T., Munro, M., \& Wiebe, G. (1998). Evidence in favor of a broad framework for Pronunciation instruction. Language Learning, 48(3), 393-410.

Derwing, T., \& Munro, M. (1997). Accent, intelligibility, and comprehensibility. Evidence from four L1s. Studies in Second Language Acquisition. 19(1), 1-16.

Deterding, D., \& Kirkpatrick, A. (2006). Emerging South-East Asian Englishes and intelligibility. World Englishes, 25(3/4), 391-409.

Dlaska, A., \& Krekeler, C. (2008). Self-assessment of pronunciation. System, 36, 506516.

Dyers, C., \& Abongdia, J-F. (2010). An exploration of the relationship between language attitudes and ideologies in a study of Francophone students of English in Cameroon. Journal of Multilingual and Multicultural Development, 31(2), 119.

Eberhard, J. P. (Producer), \& Artenstein, I. (Director). (1988). Break of Dawn. United 


\section{States: Vanguard Cinema.}

Emes, C., \& Cleveland-Innes, M. (2003). A journey toward Learner-centered curriculum. The Canadian Journal of Higher Education, 33(3), 47-70.

Faez, F., \& Valeo, A. (2012). TESOL teacher education: Novice teachers' perceptions of their preparedness and efficacy in the classroom. TESOL Quarterly, 46(3), 450471.

Farrell, T., \& Martin, S. (2009). To teach standard English or World Englishes? A balanced approach to instruction. English Teaching Forum, 2, 2-7.

fHg3iii (2012). World Englishes on TED. Retrieved from https://www.youtube.com/watch?v=LBYsuohdKs4

Flege, J. E. (1988). Factors affecting degree of perceived foreign accent in English sentences. J. Acoustical Society of America, 84(1), 70-79.

Fox, C. A. (2002). Incorporating variation in the French classroom: A pedagogical norm for Listening comprehension. In S. M. Gass, K. Bardovi-Harlig, S. M. Magnan, \& J. Walz (Eds.), Pedagogical norms for second and foreign language learning and teaching: Studies in honour of Albert Valdman (pp. 201-219). Amsterdam: Benjamins.

Gatbonton, E. (2000). Investigating experienced ESL teachers' pedagogical knowledge. Canadian Modern Language Review, 56(4), 585-616.

Giles, H., Coupland, N., \& Coupland, J. (1991). Accommodation theory: communication, context and consequences. In Giles, H., Coupland, J., \& Coupland, J. (Eds.), Contexts of Accommodation (pp. 1-68). Cambridge: Cambridge University Press. 
Gnutzmann, C. (2000). Lingua franca. In Byram, M. (Ed.) The Routledge Encyclopedia of Language Teaching and Learning. London: Routledge (pp. 356-350).

Golombek, P. (1998). A study of language teachers' personal practical knowledge. TESOL Quarterly, 32(3), 447-464.

Hackl, W. (1991). Regional variations and listening comprehension. Bulletin CILA, 53, $83-85$.

Hertel, T., \& Sunderman, G. (2009). Student attitudes toward native and non-native language instructors. Foreign Language Annals, 42, 468-482.

Hino, N. (2012). Participating in the community of EIL users through real-time news: Integrated practice in teaching English as an International Language (IPTEOL). In A. Matsuda (Ed.), Principles and Practices of Teaching English as an International Language (pp. 183-200). Bristol: Multilingual Matters.

Jenkins, J. (2011). Review of the developments in research into English as a lingua franca. Language Teaching, 44(3), 281-315.

Jenkins, J. (2009). World Englishes. A source book for students. New York, NY: Routledge.

Jenkins, J. (2006). The spread of English as an international language: A testing time for testers. ELT Journal, 60, 42-50.

Jenkins, J. (2005). Implementing an international approach to English pronunciation: The role of teacher attitudes and identity. TESOL Quarterly, 39(3), 535-543.

Jenkins, J (2002). A sociolinguistically based, empirically researched pronunciation syllabus for English as an International Language. Applied Linguistics, 23(1), 83103. 
Jusoh, M., Simun, M., \& Chong, S. (2011). Expectation gaps, job satisfaction, and organizational commitment of fresh graduates. Roles of graduates, higher learning institutions and employers. Education \& Training, 53(6), 515-530.

Kachru, B. (1996). World Englishes: Agony and Ecstasy. Journal of Aesthetic Education, 30(2), 135-155.

Kachru, B. (1990). The alchemy of English: The spread, functions, and models of nonnative. Urbana, IL: University of Illinois Press.

Kachru, B. (1985). Standards, codification and sociolinguistic realism: the English language in the outer circle. In R. Quirk, \& H. Widdowson (Eds.), English in the world: Teaching and learning the language and literatures: Papers of an international conference entitled "Progress in English Studies" held in London, 17-21 September 1984 to celebrate the Fiftieth Anniversary of The British Council and its contribution to the field of English Studies over fifty years (pp. 1130). Cambridge: Cambridge University Press.

Kachru, B. (1984). World Englishes and the teaching of English to non-native speakers: Contexts, attitudes and concerns. TESOL Newsletter, 18(22), 1-211.

Kamisili, S., \& Dugan, S. (1997). Nonnative speakers' speech perception of native speakers.

Kang, O. (2015). Learners' perceptions toward pronunciation instruction in Three Circles of World Englishes. TESOL Journal, 6(1), 59-80.

Kanno, Y., \& Applebaum, S. D. (1995) ESL students speak up: Their stories of how we are doing. TESL Canada Journal, 12(2), 32-49.

Kelch, K., \& Santana-Williamson, E. (2002). ESL Students' attitudes toward native-and- 
nonnative-speaking instructors' accents. The CATESOL Journal, 14(1), 57-72.

Kirkpatrick, A. (2007). World Englishes: Implications for international communication and English language teaching. Cambridge, UK: Cambridge University Press.

Kubota, R. (2001). Teaching World Englishes to native speakers of English in the USA. World Englishes, 20(1), 47-64.

Kubota, R., \& Ward, L. (2000). Exploring linguistic diversity through World Englishes. The English Journal, 69(6), 80-86.

Kumaravadivelu, B. (2003). Beyond methods: Macroestrategies for language teaching. New Haven, CT and London, UK: Yale University Press.

Kraut, R., \& Wulff, S. (2013). Foreign-accented speech perception ratings: a multifactorial case study. Journal of Multilingual and Multicultural Development, $34(3), 249-263$.

Lenneberg, E. (1967). Language in the context of growth and maturation. In E. Lenneberg (Ed.), Biological foundations of language (pp. 125-187). New York, NY: Wiley.

Levis, M. (2005). Changing contexts and shifting paradigms in pronunciation teaching. TESOL Quarterly, 39(3), 369-377.

Levis, J. (1999). Intonation in theory and practice, revisited. TESOL Quarterly, 33(1), 37-63.

Libben, G., \& Rossman-Benjamin, T. (1992). TESL methodology in Canada: A study of instructor attitudes and correlates. TESL Canada Journal, 9(2), 9-29.

Lippi-Green, R. (2011). English with an accent: Language, ideology and discrimination in the United States. Hoboken, NJ: Taylor \& amp; Francis. 
Litzenberg, J. (2014). Pre-service teacher perspectives towards pedagogical uses of nonnative and native speech samples. International Journal of Applied Linguistics, 122.

LoCastro, V. (2001). Individual differences in second language acquisition: Attitudes, learner subjectivity, and L2 pragmatic norms. System, 29, 69-89.

Madden, M., \& Moore, Z. (1997). ESL students' opinions about instruction in pronunciation. Texas Papers in Foreign Language Education, 3(1), 15-32.

Marinova-Todd, S., Marshall, D. B., \& Snow, C. (2000). Three misconceptions about age and L2 learning. TESOL Quarterly, 34(1), 9-34.

Matsuda, A. \& Duran, C. S. (2012). EIL activities and tasks for traditional English classrooms. In A. Matsuda (Ed.), Principles and Practices of Teaching English as an International Language (pp. 201-237). Bristol: Multilingual Matters.

Matsuda, A. \& Friedrich, P. (2012). Selecting an instructional variety for an EIL curriculum. In A. Matsuda (Ed.), Principles and Practices of Teaching English as an International Language (pp. 17-27). Bristol: Multilingual Matters.

Matsuda, A. (2003). Incorporating World Englishes in teaching English as an International Language. TESOL Quarterly, 37(4), 719-729.

McArthur, A. (1987). The English languages? English Today, 11, 9-13.

Michieka, M. (2009). Expanding Circles within the Outer Circle: The rural Kisii in Kenya. World Englishes, 28(3), 352-364.

Morley, J. (1991). The pronunciation component in teaching English to speakers of other Languages. TESOL Quarterly, 25(3), 481-520.

Murphy, J. (2013). Intelligible, comprehensible, non-native models in ESL/EFL 
pronunciation teaching. System, 42, 258-269

Murphy, J. (1997). Phonology courses offered by MATESOL programs in the U.S. TESOL Quarterly, 31(4), 741-764.

Nair, M. (Producer), \& Nair, M. (Director). (1992). Mississippi Masala. United States, United Kingdom: SCS Films.

Nelson, G. (1998). Intercultural communication and related courses taught in TESOL masters' degree programs. International Journal of Intercultural Relations, 22(1), 17-33.

Nunan, D. (1986). Seeing it their way: Learners and language curricula. Paper presented at the annual meeting of the Teachers of English to Speakers of Other Languages $\left(20^{\text {th }}\right.$, Anaheim, CA, March 3-9, 1986).

Ochsner, R. (1980). Job-related aspects of the M.A. In TESOL degree. TESOL Quarterly, 14(2), 199-207.

O’Donnell, L. \& Hayashi, D. (Producers) \& Okazaki, S. (Director). (1987). Living on Tokyo Time. United States: MGM.

Palmer, P. (2007). The Courage to teach: Exploring the inner landscape of a teacher's life. San Francisco, CA: Jossey-Bass.

Pardo, J. \& Remez, R. (2006). The perception of speech. Handbook of Psycholinguistics, $2^{\text {nd }}$ edition, 201-248.publisher and place of publication Perceptions. (2005). In Oxford English Dictionary. (3rd ed.)

Pickering, L. (2006). Current research on intelligibility in English as a lingua franca. Annual Review of Applied Linguistics, 26, 219-233.

Richards, J. (1996). Teachers' maxims in language teaching. TESOL Quarterly, 30(2), 
281-296.

Richards, J., Tung, P., \& Ng, P. (1992). The culture of the English language teacher: A Hong Kong example. RELC Journal, 23(1), 81-102.

Rossiter, M. (2009). Perceptions of L2 fluency by native and non-native speakers of English. The Canadian Modern Language Review, 65(3), 395-412.

Sakai, S., \& D'Angelo, J. F. (2005). A vision for World Englishes in the Expanding Circle. World Englishes, 24(3), 323-327.

Sayer, P. (2012). Ambiguities and tensions in English language teaching. Portraits of EFL teachers as legitimate speakers. New York, NY: Routledge.

Schaetzel, K., \& Ling, E. (2009). Teaching pronunciation to adult language learners. Center for Applied Linguistics, 1-8.

Seidlhofer, B. (2004). Research perspectives on teaching English as a lingua franca. Annual Review of Applied Linguistics, 24, 209-239.

Seidlhofer, B. (2001). Closing a conceptual gap: The case for a description of English as a lingua franca. International Journal of Applied Linguistics, 11(2), 133-158.

Seidlhofer, B. (1999). Double standards: Teacher education in the Expanding Circle. World Englishes, 18(2), 233-245.

Shulman, L. (1987). Knowledge and teaching: Foundations of the new reform. Harvard Educational Review, 57(1), 1-21.

Siegel, T. (Producer). (1986). Blue Collar \& Buddha. United States: Siegel Productions.

Sifakis, N., \& Sougari, A-M. (2005). Pronunciation issues and EIL pedagogy in the periphery: A survey of Greek state school teachers' beliefs. TESOL Quarterly, 
39(3), 467-488.

Sifakis, N. (2004). Teaching EIL-Teaching International or Intercultural English? What teachers should know. System, 32, 237-250.

Steinbach, M., \& Kazarloga, V. (2014). Square headed frogs and world citizen attitudes and identities of ESL teacher candidates in Quebec. Journal of Language, Identity and Education, 13(5), 319-334.

Sternberg, T., Wang, W., \& Yung, D. (Producers); Wang. W. (Director). (1985). Dim Sum: A Little Bit of Heart. United States: Koch Lorber Films.

Strevens, P. (1980). Teaching English as an International Language: From practice to principle. New York, NY: Pergamon Press

Sung-Yul Park, J., \& Wee, L. (2009). The three circles redux: A market-theoretic perspective on World Englishes. Applied Linguistics, 30(3), 389-406.

Teachers of English to Speakers of Other Languages. (2004). Directory of teacher education programs in TESOL in the United States and Canada. Alexandria, VA.

Thomas, A. (Producer), \& Nava, G. (Director). (1984). El Norte. United Kingdom, United States: American Playhouse, Channel Four Films, Independent Productions, Island Alive, Public Broadcasting Service.

Tokumoto, M. \& Shibata, M. (2011). Asian varieties of English: Attitudes toward pronunciation. World Englishes, 30(3), 392-408.

Tominaga, Y. (2011). An analysis of English pronunciation of Japanese learners: From the viewpoint of EIL. Pan-Pacific Association of Applied Linguistics, 15(2), 4557. 
Van Lier, L. (1995). Introducing language awareness (Penguin English applied linguistics). London; New York: Penguin English.

Wei, M., \& Educational Resources Information Center. (2006). A literature review on strategies for teaching pronunciation. S.1.: Distributed by ERIC Clearinghouse.

Whitaker, T., Whitaker, B., \& Lumpa, D. (2009). Motivating and inspiring teachers. The educational leader's guide for building staff morale. Larchmont, NY: Eye on Education.

Widdowson, H.G. (1994). The ownership of English. TESOL Quarterly, 28(2), 377-389.

Yano, Yasukata. (2001). World Englishes in 2000 and beyond. World Englishes, 20(2), $119-131$.

Yoshikawa, H. (2005). Recognition of World Englishes: Changes in Chukyo University students' attitudes. World Englishes, 24(3), 351-360. 


\section{Appendices}

\section{Appendix A: Teacher Surveys}

Q1 How old are you?

○ $20-25(1)$

- $26-30(2)$

○ $31-36(3)$

O $37-43(4)$

O $44-50(5)$

O $51+(6)$

Q2 Are you?

O Male (1)

Female (2)

Other (3)

Q3 Is English your first language?

O Yes. (1)

No. My first language is (2)

Q4 If English is your first language, do you speak English with an accent?

Yes. How would you describe your accent? (1)

No. (2)

Q5 If English is not your first language, do you speak English with an accent?

Yes. How would you describe your accent? (1)

No. (2)

Q6 What is the highest level of TESOL training you have received, if any? When and where did you receive this training?

Q7 Have you ever lived and/or taught English outside the United States?

a) Yes. (Where, when, for how long) (1)

No. (2)

Q8 Have you ever taught English pronunciation?

Y Yes (1)

No (2) 
Q9 What type of pronunciation did you teach?

American English (1)

British English (2)

Other dialect/s. Please explain. (3)

Q10 Are you satisfied with the amount of classroom time you're able to dedicate to pronunciation instruction? Please elaborate if necessary.

Yes. (1)

No. (2)

The following questions relate to your teaching practice with regard to World Englishes. Please elaborate on your responses in the spaces provided, as needed.

Q1 Did you receive World Englishes-related instruction during TESOL training or at any time before today?

Yes. When/Where? Please explain the type of training you received. (1)

O No. (2)

Q2 Have you ever incorporated World Englishes pronunciations perspectives into your classroom activities, lesson plans, or materials?

Y Yes. (1)

No. (2)

Q3 How, and how often, did you incorporate World Englishes pronunciation perspectives into your classroom activities, lesson plans, or materials?

Q4 How important is it to you personally to receive training and/or to learn about World Englishes or other "non-native" speaker pronunciation perspectives?

V Very unimportant. (1)

Somewhat unimportant. (2)

Somewhat important. (3)

Very important. (4)

Q5 I feel it is to teach ESL students about World Englishes pronunciations (e.g. Singapore English, Indian English, etc.)

Very unimportant (1)

Somewhat unimportant (2)

Somewhat important (3)

Very important (4) 
Q6 How important is it for your professional development that you receive World Englishes or other nonnative speaker pronunciation perspectives training?

\section{Very unimportant (1)}

Somewhat unimportant (2)

Somewhat important (3)

Very Important (4)

Q7 It is that speakers of English as their second language can be successful in the English-speaking world even if they cannot fully understand how other English speakers, native or nonnative, pronounce English.

Completely untrue (1)

Somewhat untrue (2)

Somewhat true (3)

Completely true (4)

Q8 Regardless of whether or not you have received World Englishes training, how important is it to you to incorporate World Englishes perspectives into your lessons, materials, or into your practice in general?

Very unimportant (1)

Somewhat unimportant (2)

Somewhat important (3)

Very important (4)

Q9 It is that speakers of English as their second language can be successful in the English-speaking world even if they pronounce English with an accent.

Completely untrue (1)

Somewhat untrue (2)

Somewhat true (3)

Completely true (4)

Q10 What is "good pronunciation" when it comes to speakers of English as a Second Language?

That they speak well enough so you can't tell they are ESL speakers. (1)

That they speak well enough so that they can be understood. (2)

Other. Please explain. (3)

Please watch the following video in its entirety before moving on to the next block of questions. The video is roughly 4 minutes long. 
Q1 Do you feel the video you just watched or similar material related to World Englishes would be beneficial in your classroom?

O Yes. (1)

No. (2)

Q2 I feel that it is that students learn about World Englishes and/or non-native English pronunciation perspectives.

Very unimportant (1)

Somewhat unimportant (2)

Somewhat important (3)

Very Important (4)

Q3 It is for me personally to get training and/or learn about World Englishes or other non-native pronunciation perspectives.

Very unimportant (1)

Somewhat unimportant (2)

Somewhat important (3)

Very Important (4)

Q4 How important is it for your students' ability to be successful English speakers to be familiar with English accents from around the World?

V Very unimportant. Please explain. (1)

Somewhat unimportant. Please explain. (2)

Somewhat important. Please explain. (3)

Very important. Please explain. (4)

Q5 In your opinion, do the speakers in the video have "good pronunciation"?

O Yes. (1)

O No. (2)

Other. Please explain. (3)

Q6 In your opinion, how important is it to incorporate World Englishes pronunciation perspectives into the ESL curricula?

Very unimportant (1)

Somewhat unimportant (2)

Somewhat important (3)

V Very important (4) 
Q7 It is that my students can be successful English speakers even if they have an accent.

Completely untrue (1)

O Somewhat untrue (2)

Somewhat true (3)

Completely true (4)

Q1 Would you like to be entered into a drawing for a chance to win one of seven $\$ 10$ gift cards?

Yes. Please provide your name and email address on the next page. (1)

No (2)

Q2 Please provide your information

Name (1)

Email address (2)

Q3 Please choose one from the following:

○ Target (1)

Starbucks (2)

Amazon (3) 


\section{Appendix B: Student Surveys}

Q1 How old are you?

O $18-21(1)$

○ $22-25(2)$

○ $26-29(3)$

○ $30-34(4)$

O $35-39(5)$

○ $40-44(6)$

O $45+(7)$

Q2 Are you?

O Male (1)

Female (2)

Other (3)

Q3 What is your first language?

Q4 How long have you lived in the United States?

O $0-5$ months (1)

- 6 months- 1 year (2)

- 1-3 years (3)

3-5 years (4)

- 5-10 years (5)

O $10+$ years $(6)$

Q5 How long have you been studying English in the US?

O $0-5$ months (1)

O 6 months- 1 year (2)

- 1-2 years (3)

- $2+$ years (4)

Q6 Who do you most often speak English with in the US?

Family/Friends. (1)

Coworkers. (2)

Teachers and other English students. (3)

Other. Please explain. (4) 
Q7 Do/did you speak English in your home country?

Yes. With whom? (1)

No. (2)

Q8 I live in the United States

P Permanently. (1)

Temporarily. I plan to go back to my home country when/after. (2)

Prefer not to answer. (3)

Q9 I usually tell who speaks English as their first language and who does not.

- can (1)

can not (2)

Q10 Have you ever taken an English pronunciation class?

Y Yes. (1)

No. (2)

Q11 When and where did you study pronunciation? What type of pronunciation did you learn (American, British English, other pronunciation)?

Q12 Are you satisfied with the amount of English pronunciation instruction you receive on a regular basis/during class?

O Yes. (1)

No. (2)

Q13 Have you ever learned about other English pronunciations besides American or British English pronunciations (for example, Singapore or Indian English)?

Y Yes. Where, what pronunciations? (1)

No. (2)

Q1 Do you have an accent?

Y Yes. (1)

O No. (2)

Sometimes. (3) 
Q2 Which best describes how you feel about your accent?

a) I like my accent. I am fine speaking with an accent. (1)

b) I don't like my accent. I would lose my accent if I could. (2)

c) I would like to speak like a native speaker (someone who learned English as their first language). (3)

d) I would like to change/improve my accent, but I don't need/want to sound like a native speaker (someone who learned English as their first language). (4)

Q3 Do you think it is possible for people who have accents to be successful in the English speaking world?

Yes. Please explain. (1)

No. Please explain. (2)

Q4 What do you consider "good pronunciation" to be?

a Speaking well enough so that other people don't know English isn't my first language. (1)

b) Speaking well enough so that other people can understand me. (2)

c) Other. Please explain (3)

Q5 Would you like to learn about English pronunciations from around the world? (this question is not about you learning to speak with a Singaporean or an Indian English accent, it's about whether or not you would be interested in a lesson or in taking a class where you can learn about other English accents, the people who speak with those accents, their culture, etc.)

Yes. (1)

No. (2)

Other. Please explain. (3)

Q6 Would you like your teachers to use (more) materials that include English speakers from around the world, in addition to speakers from the US?

O Yes. (1)

No. (2)

My teachers already use materials with English speakers from around the world. (3)

Q7 Do you think you can be successful in the English-speaking world even if you don't fully understand the way English speakers pronounce English (consider both people who have been speaking English all their lives, and people who speak English as their second language)?

Yes. Please explain. (1)

No. Please explain. (2) 
Q8 Without taking into account if you, personally, would or would not take a class on English pronunciations from around the world, how important is it to you that your teachers are familiar with this topic?

Very unimportant. (1)

Unimportant. (2)

Important. (3)

Very important. (4)

Please watch the following video from beginning to end before moving on to the next block of questions. The video is roughly 4 minutes long

Q1 What types of English pronunciations did you hear in the video? (It is not important to list every pronunciation variety ("accent"), or to get the varieties "right". I am interested in learning if you can identify any varieties besides American English. Please list as many as you can.

Q2 I tell who in the video speaks English as their first language (since birth), and who does not.

\section{Can (1) \\ Can not (2)}

Q3 How would you describe your pronunciation?

I have an accent. (1)

I don't have an accent. (2)

Sometimes I speak with an accent, sometimes I can sound like an American English speaker. (3)

Q4 Which best describes how you feel about your accent?

a) My English accent is a part of who I am. I would like to keep my accent. (3)

b) My English accent is not a part of who I am. I would like to lose my accent. (4)

c) Other. Please explain. (5)

Q5 Is it important for you to learn about the way other people speak English? For example, would you take a class titled "Accents of the World" or "English around the World"? (Please note: This class would not teach you to speak with any one particular accent. You would only learn about other English accents in addition to American or British English, etc.)

Y Yes. Please explain. (1)

No. Please explain. (2)

Q6 What do you consider "good pronunciation"?

a) Speaking clearly enough that other people understand me. (1)

b) Sounding like I have been speaking English since I was born. (2)

c) I'm not sure. (3)

Q7 Do you think it is possible for people to be successful in the English-speaking world even if they 
pronounce English with an accent?

Y Yes. (1)

O No. (2)

Other. Please explain. (3)

Q8 Would you like your teachers to use materials regarding World Englishes, similar to the video you just watched, in class?

Yes. (1)

No. (2)

My teachers already use similar materials where I can hear other English accents. (3)

Q9 Do you think you can be successful in the English-speaking world even if you don't understand everything people with accents, such as those in the video, say?

Y Yes. (1)

O No. (2)

Other. Please explain. (3)

Q10 Do you think it's important your teachers receive training/learn about many varieties of English pronunciations from around the world, such as those you saw in the video?

Y Yes. (1)

No. (2)

Other. Please explain. (3)

Q1 Would you like to be entered into a drawing for a chance to win one of ten- $\$ 10$ gift cards?

Yes. You will need to provide your name and email address. (1)

O No. (2)

Q2 Please provide your information:

Name (1)

Email address (2)

Q3 If your name is selected, please choose the store you would like to receive your gift card from.

Target (1)

O Starbucks (2)

- Amazon (3) 


\title{
Appendix C: Invitation to Participate
}

\author{
Dear (MW/NW) ESL Faculty
}

My name is Marie Arrieta and I'm a student in the MA TESOL program at Portland State University in Portland, Oregon. I am conducting a study on the perceptions and attitudes ESL teachers and students have regarding World Englishes pronunciations, and I would like to recruit (MW/NW) ESL teachers and students for my study. The only requirement for your participation is that you be an (MW/NW) instructor currently teaching at least one (any level) ESL class at the time you take the survey. If you are currently teaching courses in level 4 or above and think your students might benefit from being a part of the study, please forward the attached letter to them.

Your participation is completely voluntary, and it would involve answering a survey and watching a short 4 minute video. You may withdraw from the study at any time, even after starting the survey. Your participation may be anonymous, or you may choose to be entered into a drawing to win 1 of $7 \$ 10$ gift cards for your time. You will need to provide your name and email address if you choose to enter the drawing.

This study has been approved by (MW/NW)'s IRB Committee Chair.

If you have any questions, please email me at arriet@pdx.edu

If you would like to take the survey, please click on the link below:

https://portlandstate.qualtrics.com/SE/?SID=SV 8eS86FZsso0RCyV

Thank you for considering being part of this study!

Marie Arrieta 


\title{
Appendix D: Teacher Consent
}

\author{
(MW/NW) Teacher World Englishes Survey
}

You are about to take part in a World Englishes pronunciations study. Your participation is voluntary; you may withdraw from this study at any time. If you decide to participate, please follow the instructions and complete all parts of the survey. The survey consists of roughly 30 questions and one 4-minute video. Only the first ten teachers to submit their completed surveys are eligible to be entered into a drawing to win 1 of 7-\$10 gift cards. If you choose to enter the drawing, you will need to provide your name and email address at the end of the survey.

By agreeing to fill out this survey, you acknowledge that you are an ESL instructor currently teaching at least one class at (MW/NW). Thank you for participating!

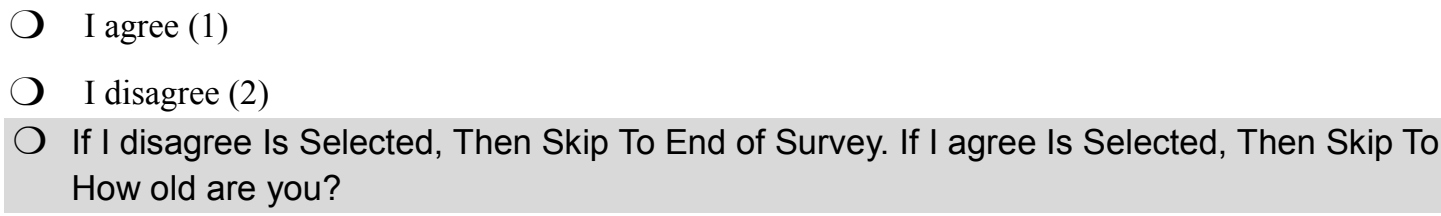




\title{
Appendix E: Student Consent
}

\author{
(MW/NW) Student World Englishes Survey
}

You are about to take part in a study regarding World Englishes accents. Your participation is voluntary and will in no way affect your grades and/or your performance in your class/es. You may stop taking the survey at any time, even after starting it. The study consists of a survey of about 30 questions, plus a 4 minute video. If you decide to participate, please follow the instructions and complete all parts of the survey to the best of your knowledge. There are no "right" or "wrong" answers. Your participation will be completely anonymous, unless you choose to be entered into a drawing to win one of ten $\$ 10$ gift cards of your choosing. If so, you will need to provide your name and email address at the end of the survey. Only the first 20 students to successfully submit their survey may be entered into the drawing. By agreeing to fill out this survey, you acknowledge that you are at least 18 years of age and a student of English as a Second Language enrolled in at least one (MW/NW) course Level 4 or above. Thank you for participating!
I agree (1)
I disagree (2)
If I disagree Is Selected, Then Skip To End of Survey. If I agree Is Selected, Then Skip To How old are you? 